\title{
Hardiness, perseverative cognition, anxiety, and health-related outcomes: A case for and against psychological hardiness
}

Christopher M. Kowalski, The University of Western Ontario

Supervisor: Schermer, Julie A., The University of Western Ontario

A thesis submitted in partial fulfillment of the requirements for the Master of Science degree in Health and Rehabilitation Sciences

(C) Christopher M. Kowalski 2018

Follow this and additional works at: https://ir.lib.uwo.ca/etd

Part of the Health Psychology Commons, and the Personality and Social Contexts Commons

\section{Recommended Citation}

Kowalski, Christopher M., "Hardiness, perseverative cognition, anxiety, and health-related outcomes: A case for and against psychological hardiness" (2018). Electronic Thesis and Dissertation Repository. 5385.

https://ir.lib.uwo.ca/etd/5385

This Dissertation/Thesis is brought to you for free and open access by Scholarship@Western. It has been accepted for inclusion in Electronic Thesis and Dissertation Repository by an authorized administrator of Scholarship@Western. For more information, please contact wlswadmin@uwo.ca. 


\begin{abstract}
The present study investigates the utility of psychological hardiness as well as the differences between rumination and worry. Undergraduate students completed questionnaires assessing hardiness, worry, rumination, mindfulness, neuroticism, anxiety, somatization, coping, and health. Correlations and partial correlations controlling for neuroticism were examined. Hardiness was negatively correlated with neuroticism, rumination, worry, and anxiety and positively correlated with mindfulness, coping, and health. When neuroticism was statistically controlled, the relationships between hardiness and rumination, health, and coping became nonsignificant, and the relationships between hardiness and worry, mindfulness, and anxiety although attenuated, remained significant. Rumination and worry positively correlated, but when neuroticism was statistically controlled, this relationship became nonsignificant. The results suggest that hardiness is better conceptualized as a personality style that contributes to psychological well-being. Furthermore, our findings suggest that rumination and worry are distinct cognitive processes.
\end{abstract}

Keywords: Hardiness, rumination, worry, mindfulness, health 


\section{Acknowledgments}

Firstly, I would like to thank my supervisor, Dr. Julie Aitken Schermer, for all of her help and guidance over the past few years. I will always be grateful for the opportunities she has given me and for everything that I have learned from her, and I look forward to continuing working under her mentorship. Without her, I would have never found my passion for the study of personality.

I would also like to thank Jessica Kwiek for assisting me with the data collection and Kasia Wojnowska for comments on a previous version of this thesis. I am very thankful for the time and effort they contributed to this project.

The author acknowledges financial assistance from the Dancap Private Equity Research Award in the DAN Department of Management and Organizational Studies, Faculty of Social Science, The University of Western Ontario for the collection of the data. 


\section{Table of Contents}

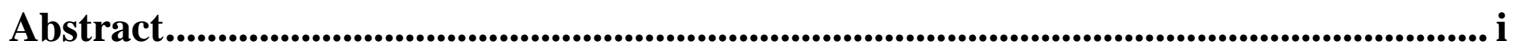

Acknowledgments ................................................................................................................................... ii

Table of Contents .....................................................................................................................iii

List of Tables ................................................................................................................................... v

List of Appendices........................................................................................................ vi

Chapter 1: Introduction ....................................................................................................................... 1

1.1 Psychological Hardiness................................................................................................ 1

1.2 Trait Mindfulness ................................................................................................... 3

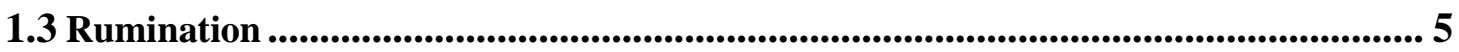

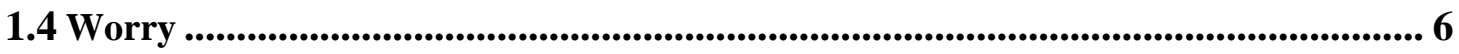

1.5 Present Study ....................................................................................................................... 7

Chapter 2: Methods ................................................................................................................................ 11

2.1 Participants......................................................................................................................... 11

2.2 Materials ........................................................................................................................................... 11

2.2.1 Hardiness ............................................................................................................................... 11

2.2.2 Mindfulness ......................................................................................................................... 12

2.2.3 Rumination ............................................................................................................... 12

2.2.4 Worry ............................................................................................................................ 13

2.2.5 Neuroticism......................................................................................................................... 14

2.2.6 Anxiety ....................................................................................................................... 14

2.2.7 Health ................................................................................................................................... 15

2.2.8 Coping ................................................................................................................... 15

2.3 Procedure.................................................................................................................................... 15 


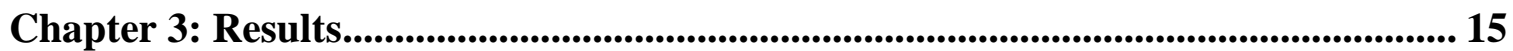

3.1 Descriptive Statistics...................................................................................................... 15

3.2 Sex Differences and Correlatations with Age........................................................... 17

3.3 Exploratory Factor Analysis ........................................................................................ 20

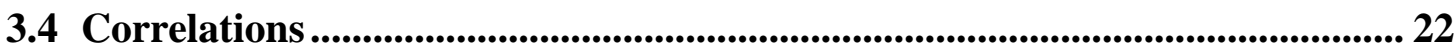

3.5 Partial Correlations ..................................................................................................... 26

Chapter 4: Discussion ..................................................................................................................... 29

4.1 Limitations and Further Directions ....................................................................... 32

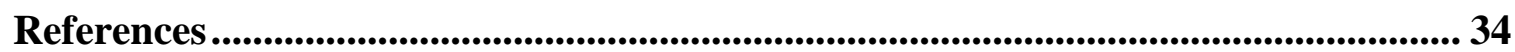

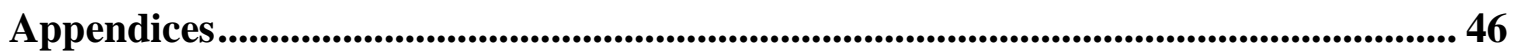

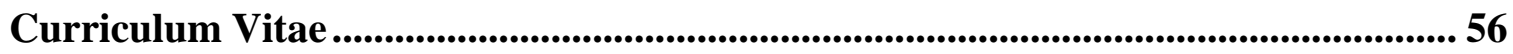


List of Tables

Table 1: Descriptive Statistics and Reliability........................................................................ 15

Table 2: Sex Differences and Correlations with Age............................................................ 18

Table 3: Factor Analysis Pattern Matrix.................................................................................. 20

Table 4: Intercorrelations Between All Measures and Facet Scores ............................ 24

Table 5: Partial correlations, controlling for neuroticism, between all measures .... 26 


\section{List of Appendices}

Appendix A: SONA description........................................................................................... 45

Appendix B: Letter of Information and Consent Form .............................................. 46

Appendix C: Debriefing Form ................................................................................................ 49

Appendix D: Ethics Approval.............................................................................................. 50 


\section{Introduction}

The relationship between stress and health has been a research question in both health psychology and the health sciences fields. Typically, the correlation between stress and illness is weak (Rabkin \& Struening, 1976; Rodenberry \& Renk, 2010), however a description of this relationship based mainly on the correlation would be overly simplistic as the relationship is immensely complicated, among other reasons, by a plethora of moderators (e.g., physical fitness, exercise, beliefs about mood, self-complexity, social support, etc.; Brown, 1991; Carmack, de Moor, Boudreaux, Amaral-Melendez, \& Brantley, 1999; Goldman, Kraemer, \& Salovey, 1996; Gore, 1978; Linville, 1987). For decades, researchers have been studying how stress influences health and illness. Of particular interest to this paper, is the contribution of personality psychology to this literature. More specifically, the present study investigates the concept of psychological hardiness and how it relates to stress, health, and other stress-related personality traits.

\section{Psychological hardiness}

First introduced in Kobasa's (1979a) seminal work, hardiness is a personality style that characterizes individuals who remain healthy (defined as the absence of illness) under stressful conditions, relative to individuals who tend to fall ill when experiencing stress. Hardiness is comprised of three related general characteristics: control, commitment, and challenge. Kobasa, Maddi, and Kahn (1982) describe the control element of hardiness as a tendency to believe that one can control or influence the events that one encounters. Perceptions of control influence stress resistance as events and actions are more likely to be perceived as natural consequences of one's actions, rather than unexpected and overwhelming experiences. The commitment element is described as the tendency to feel profoundly committed to or involved in the activities in 
which one participates. Commitment is theorized to enhance stress resistance as individuals who are committed to themselves, their activities, and/or their environments are less likely to give up under pressure as they are invested in the object of their commitment. In other words, commitment motivates active approach strategies as opposed to passive avoidant strategies used to deal with stress. Lastly, the challenge aspect is defined as the tendency to perceive change as an exciting challenge rather than as a threat. Challenge alters the cognitive appraisal of a potentially stressful situation from a negative appraisal (a source of distress to resist) to a positive appraisal (an opportunity for growth and something to be conquered; Kobasa et al., 1982). Kobasa, Maddi, and Courington (1981) posit that the enhanced psychological resilience characteristic of hardiness is not necessarily a product of the effects of individual components, but rather a collection or combination of various styles of coping.

Indeed, Kobasa and colleagues (Kobasa, 1979a, 1979b; Kobasa, et al, 1981; Kobasa, et al., 1982) demonstrated that individuals who scored lower on hardiness measures had a greater tendency to become ill when experiencing high levels of stress compared to hardy individuals. Similarly, a study by Kobasa, Maddi, Pucetti, and Zola (1985) suggested that hardiness was a stronger predictor of illness than exercise and social support. In other words, the findings suggest that hardiness is better at buffering the effects of stress on health than exercise and social support. Other studies have also shown that hardiness is a significant predictor of mental health in real-life stress (Neria, et al., 2001), active coping and effort strategies (Hanton, Neil, \& Evans, 2013), and is associated with physical health, with this relationship being mediated by mental health (Taylor, Pietrobon, Taverniers, Leon, \& Fern, 2013).

The concept of hardiness has faced some criticisms. Some research has raised concerns that hardiness is a redundant concept that measures neuroticism (Funk, 1992). One reason for 
this concern is that many of the items used in hardiness scales (e.g., the Dispositional Resilience Scale; DRS; Bartone, Ursano, Wright, \& Ingraham, 1989) resemble items that tap into neuroticism (see Funk, 1992 for a list of hardiness items and the corresponding neuroticism items). This criticism is particularly problematic for researchers investigating hardiness as the effect of hardiness on somatic complaints could be explained by the tendency of neurotic individuals to over-report their symptoms (Costa \& McCrae, 1987). Consistently, studies investigating the relationship between hardiness and neuroticism have found moderate correlations suggesting that despite considerable overlap, hardiness is not a duplicate dimension of neuroticism (Funk \& Houston, 1987; Klag \& Bradley, 2004; Manning, Williams, \& Wolfe, 1988; Nowack, 1986; Parkes \& Rendall, 1988). Some researchers have attempted to further address this concern by controlling for neuroticism when correlating hardiness and illness, but results have been mixed with some studies indicating that partialling out the effect of neuroticism attenuated this relationship (Klag \& Bradley, 2004; Sinclair \& Tetrick, 2000; see Escheleman, Bowling, \& Alarcon, 2010 for meta-analysis), and others indicating that controlling for neuroticism completely eliminates the relationship between hardiness and stress (Williams, Wiebe, \& Smith, 1992). The present study will investigate this further by examining the correlation between hardiness and neuroticism, as well as the partial correlation controlling for neuroticism, between hardiness and anxiety and health outcomes.

\section{Trait Mindfulness}

Mindfulness is defined as the tendency to be aware of one's ongoing experiences without judgement or evaluation (Kabat-Zinn, 1994). Baer, Hopkins, Krietmeyer, Smith, and Toney (2006) posited that trait mindfulness is composed of five underlying facets: (1) observing, or attention to cognitive and physical experiences; (2) describing, or the ability to verbally describe 
one's experiences; (3) acting with awareness, or attention to one's ongoing activities; (4) nonjudging of inner experience, or non-evaluation of one's thoughts, sensations, or emotions; (5) non-reactivity to inner experience, or ability to not become absorbed in one's thoughts or feelings.

Past research has demonstrated that mindfulness is associated with adaptive physiological self-regulation of stress (Kadziolka, Di Pierdomenico, \& Miller, 2016), healthier eating behaviours (Jordan, Wang, Donatoni, \& Meier, 2014), more adaptive coping (Weinstein, Brown, \& Ryan, 2009), emotional stability (Wenzel, von Versen, Hirschmuller \& Kubiak, 2015), less rumination (Ciesla, Reilly, Dickson, Emanuel, \& Updegraff, 2012), less substance abuse behaviours (Karyadi, VanderVeen, \& Cyders, 2014) and improved physical and mental health (Carmody, Reed, Kristeller, \& Merriam, 2008; Grossman, Niemann, Schmidt, \& Walach, 2004: Tomfohr, Pung, Mills, \& Edwards, 2015). Although the relationship between mindfulness and health has been replicated many times, using varying measures of both mindfulness and health, knowledge on the exact mechanisms that are responsible for this relationship is still lacking. Tomfohr et al. (2015) postulate that increases in trait mindfulness influence health variables (i.e., blood pressure and inflammation) by reducing physiological responses to stress. This theory is supported by other research that found that dispositional mindfulness was inversely correlated with baseline cortisol levels (a stress hormone; Jacobs et al., 2013) and moderated the effect of social stressors on cortisol levels (Brown, Weinstein, \& Cresswell, 2007). Similarly to hardiness, the relationship between mindfulness and stress is theorized to be a function of the cognitive appraisal of stressors; mindful individuals tend to perceive potential stressors as less threatening (Weinstein, et al., 2009). In contrast to hardiness, mindful individuals are not more likely to view stressful situations as challenges relative to non-mindful individuals. The present study will 
directly investigate the relationship between hardiness and mindfulness and the underlying aspects of each trait.

\section{Rumination}

Rumination is defined as a distress response characterized by passively and repetitively focusing attention on stress symptoms, causes, and consequences (Nolen-Hoeksema, 1991; See Nolen-Hoeksema, Wisco, \& Lyubomirsky, 2008, and Smith \& Alloy, 2009 for reviews). Ruminative individuals compulsively brood over their problems, but do not engage in any form of active problem solving to attend to these problems (Nolen-Hoeksema, et al., 2008).

Researchers have found associations between rumination and a wide array of negative outcomes including: depression, anxiety, diminished physical health, poor problem solving, anxiety, neuroticism, inhibition of instrumental behaviours, substance abuse, and eating disorders (Flett, Madorsky, Hewitt, \& Heisel, 2002; Kocovski, Endler, Rector, \& Flett, 2005; Lyubomorsky \& Nolen-Hoeksema, 1993, 1995; Lyubomirsky, Tucker, Caldwell, \& Berg, 1999; Muris, Roelofs, Rassin, Franken, \& Mayer, 2005; Nolan, Roberts, \& Gotlib, 1998; Nolen-Hoeksema \& Harrel, 2002; Nolen-Hoeksema, Stice, Wade, \& Bohon, 2007; Thomsen et al., 2004).

According to Nolen-Hoeksema (1991), rumination prolongs and worsens distress and depression through various processes. For example, rumination increases the effects of depressed mood on thinking, thus ruminative individuals are more likely to use thoughts and memories activated as a result of the depressed mood to understand their current situation. Rumination also interferes with problem solving by promoting a sense of helplessness and pessimism. Moreover, rumination inhibits instrumental behaviours. In other words, ruminative individuals are less likely to participate in behaviours that will improve their situation, even when they are aware that the activity will improve their mood (Lyubomirsky, \& Nolen-Hoeksema, 1993). Furthermore, 
there is evidence to suggest that rumination is related to a reduction in social support despite greater attempts to reach out to friends and relatives (Nolen-Hoeksema \& Davis, 1999). The present study will examine rumination (or rather the lack of rumination) as a potential mechanism of hardiness by examining the correlation between hardiness and rumination.

\section{Worry}

Borkovec, Robinson, Pruzinsky, and DePree (1983) defined worry as a relatively uncontrollable chain of negatively affect-valenced thoughts representing an attempt at mental problem solving. Although this is a very early attempt at defining worry and the authors note that this is a working definition that requires years of theoretical and empirical effort to improve, the definition is still widely used by many psychologists to direct their investigations of worry (Brosschot, Gerin, \& Thayer, 2006; Questret \& Cropley, 2013). Worry has been found to be associated with negative health-relevant outcomes including: high neuroticism, anxiety, depression (and has been found to partially mediate the relationships between neuroticism and anxiety and depression; Muris et al., 2005), heart problems (Brosschot, Van Dijk, \& Thayer, 2007; Kubzansky, Kawachi, Spiro, Wiess, Vokonas, \& Sparrow, 1997), insomnia (Borkovec, 1979; Borkovec et al., 1998), and is the central characteristic defining generalized anxiety disorder (GAD; American Psychiatric Association, 2000).

Although Borkovec et al. (1983) speculated that worry could potentially lead to more active and effective coping strategies, empirical evidence has contradicted this notion (Davey, 1993). Conversely, the bulk of the extant literature suggests that worry is an avoidant cognitive coping style in itself (see Borkovec et al., 1998 for review). A theorized function of worry is the avoidance of frightening stimuli; worry reduces the affective consequences of frightening imagery by verbalization. That is, by transforming mental images of fear-inducing stimuli into 
verbal cognitions (i.e. worry), the details of the fear become more abstract, less concrete, and less engaging than the initial aversive images (Borkovec et al., 1998). Verbalization reduces the physiological response, thus reducing the affective consequences of the stimulus or situation (Tucker \& Newman, 1981; Vrana, Cuthbert, \& Lang, 1986). This reduction in affective consequences can be problematic as inhibition of fearful images may interfere with the complete emotional processing essential in fear extinction (Borkovec et al., 1998). Furthermore, because the anticipated anxiety-inducing situation is often imagined or does not take place, the tendency to worry is negatively reinforced, further increasing the tendency to worry. Research by Stober and colleagues (Stober, Tepperwien, \& Staak, 2000) has supported the theory that worry is a form of cognitive avoidance; they found that individuals who explained situations associated with greater levels of worry tended to give less concrete elaborations of the object of their anxiety. Comparably, Stober and Borkovec (2002) found that individuals with GAD who were treated with cognitive-behavioural therapy tended to give more vivid descriptions of the object of their worries than non-treated individuals with GAD. It is important to note however, that worry, in some cases, can be adaptive. For example, when the fear-inducing stimulus is indeed a reallife threat that does not require creative thinking to solve, worry can serve as a way to mentally prepare for this threat (Mathews, 1990). Overall, it seems that this is rather the exception to the rule and that worry is troublesome more often than it is not. The present study will contribute to the worry literature by examining the similarities and differences to other temporal orientationrelated traits (i.e. rumination and mindfulness) and by investigating worry (rather the lack of worry) as a potential mechanism of hardiness. 


\section{Present Study}

The main purpose of this study is to investigate the concept of hardiness in terms of types of temporal cognition (i.e. mindfulness, rumination, and worry). Extant research has suggested that hardiness promotes adaptive and active responses to stress (Eschleman et al., 2010; Hanton et al., 2013), so it is expected that hardiness will be negatively correlated with rumination (hypothesis 1a) and worry (hypothesis 1b), and unrelated to mindfulness (hypothesis 1c). All three cognitive tendencies are passive stress responses, and of the three, only mindfulness is inversely associated with neuroticism (Nolan et al., 1998; Muris et al., 2005; Wenzel, et al., 2015). As well, hardiness is partially based on challenge, which is in direct opposition to the acceptance aspect of mindfulness theory. Moreover, rumination and worry are considered by many researchers to be avoidant coping styles, which is inconsistent with theoretical and empirical accounts of hardiness (Borkovec et al., 1998; Eschleman et al., 2010; Kobasa et al., 1985; Smith \& Alloy, 2009). Additionally, when neuroticism is statistically controlled, it is expected that the relationships between hardiness and rumination (hypothesis 1d) and worry (hypothesis 1e) will be attenuated, but not completely eliminated. With regards to mindfulness, it is predicted that its relationship with hardiness will be negative when neuroticism is statistically controlled (hypothesis 1f). Partialling out the effect of neuroticism will address the criticism that hardiness is a redundant construct of neuroticism (Funk, 1992; Funk \& Houston, 1987). With regards to health consequences, Brosschot et al. (2006) have proposed that rumination and worry can be grouped into a broader category labeled 'perseverative cognition'. They suggest that stressful events alone have relatively small consequences on physical and mental health as they usually cause short-lived episodes of physiological arousal. Perseverative cognition, on the other hand, prolongs these physiological symptoms before (worry) and after (rumination) the stressful 
event and profoundly increases the risk of long-term health consequences. This is relevant to the present study as most of the research done thus far on the relationship between hardiness and health has focused on stressful events, and no research to our knowledge has focused on the relationship between hardiness and perseverative cognition.

The second purpose of this study is to contribute to the current body of research on the difference between rumination and worry. Overall, rumination and worry are conceptually similar, and some have argued that their underlying processes are indistinct, but they differ in their temporal orientations and function; worry is future-oriented and concerned with unresolved safety goals while rumination is past-oriented and concerned with self-understanding (Segertrom, Tsao, Alden, \& Craske, 2000; Watkins, Moulds, \& Mackintosh, 2005). Still, little is known about the differences between these traits and there have been recent attempts at better differentiating worry from rumination. Using factor analytic methodology, Fresco, Frankel, Mennin, Turk, and Heimberg (2002) successfully extracted four factors from the Penn State Worry Questionnaire (Meyer, Miler, Metzger, \& Borkovec, 1990) and the Ruminative Responses Scale from the Response Styles Questionnaire (Nolen-Hoeksema \& Morrow, 1991). None of the four factors extracted were comprised of items from both questionnaires. In other words, two of the factors (Worry Engagement, Absence of Worry) solely represented dimensions of worry, and the other two (Dwelling on the Negative, Active Cognitive Appraisal) solely represented dimensions of rumination, supporting the thesis that although worry and rumination are related, they are indeed distinct dimensions. In a similar way, Muris and colleagues (2005) found that the relationship between worry and rumination disappears after controlling for neuroticism, and that both dimensions have common and unique contributions in predicting anxiety and depression. By looking at the correlations between worry and rumination and other 
outcomes including hardiness, the present study will contribute to the literature investigating these constructs. It is predicted that rumination and worry will be significantly positively correlated (hypothesis $2 \mathrm{a}$ ) and that the correlation will become non-significant when neuroticism is statistically controlled (hypothesis $2 \mathrm{~b}$ ), consistent with the findings of Muris et al. (2005).

Regarding mindfulness, it is predicted that it will be negatively correlated with rumination (hypothesis 3a) and worry (hypothesis $3 b$ ). Conceptually, perseverative cognition is inconsistent with the notion of mindfulness as mindfulness emphasizes a present temporal orientation, acceptance, and a non-evaluative outlook (Baer et al., 2006), while worry and rumination are characterized by future and past temporal orientations, respectively, and brooding and negatively valenced thoughts (Bokovec et al., 1983; Nolen-Hoeksema, 1991). Moreover, mindfulness-based therapies have been suggested to reduce excessive worrying and rumination (Deyo, Wilson, Ong, \& Koopman, 2009; Querstet \& Cropley, 2013). This hypothesis is consistent with previous research that has suggested that rumination and worry mediate the inverse relationship between mindfulness and anxiety symptoms (Desrosiers, Vine, Klemanski, \& Nolen-Hoeksma, 2013; Frewen, Evans, Maraj, Dozois, \& Partridge, 2008). When investigating the association between mindfulness and perseverative cognition, extant research has overwhelmingly looked at mindfulness training or state mindfulness. The present study will contribute to the mindfulness literature by focusing on trait mindfulness in the context of perseverative cognition.

The present study will also investigate the relationships between hardiness, mindfulness, rumination, worry, anxiety, neuroticism, and health. Based on the reviewed literature, it is expected that hardiness and mindfulness will be positively correlated with health and coping (hardiness - hypothesis 4a; mindfulness - hypothesis 4b), and negatively correlated with anxiety 
and neuroticism (hardiness - hypothesis 4c; mindfulness - hypothesis 4d). Moreover, I predict that the correlations between hardiness and health and coping, although reduced in strength, will still be significant and positive when neuroticism is statistically controlled (hypothesis 4e). I also expect the relation between hardiness and anxiety to be weakened, but significant after removing the effect of neuroticism (hypothesis 4f). As well, it is predicted that the perseverative cognition traits will be negatively correlated with health and coping (rumination - hypothesis 5a; worry hypothesis 5b), and positively correlated with anxiety and neuroticism (rumination - hypothesis 5c; worry - hypothesis 5d). I am aware of the inflation of Type I Error when there are this many variables that are tested, but I have weighed this issue with the a priori hypotheses.

\section{Method}

\section{Participants}

The sample was comprised of 258 participants aged 17 to $61(\mathrm{M}=19.46, \mathrm{SD}=3.71 ; 155$ women, 101 men, and 2 unspecified) recruited from the DAN Management and Organizational Studies (MOS) student participant pool. Participants were compensated 1\% towards their final mark in their MOS course.

\section{Materials}

Hardiness. To measure hardiness, participants completed the Dispositional Resilience Scale (DRS; Bartone et al., 1989). The DRS is comprised of 45 items, with 15 items for each subscale (commitment, challenge, and control). Items (example items: commitment - "Ordinary work is just too boring to be worth doing"; challenge - "I don't like to make changes to my everyday schedule"; control - "Planning ahead can help avoid most future problem") on a 4point Likert style scale ranging from 0 (not at all) to 3 (completely true). Bartone et al. (1989) reported Cronbach's alpha coefficients of .85 for hardiness, .82 for commitment, .66 for control, 
and .62 for challenge. For the present study, our reliabilities were mostly comparable to Bartone et al.'s (1989; hardiness $\alpha=.81$, commitment $\alpha=.74$, control $\alpha=.67$, challenge $\alpha=.38$; and dropping an item would not improve the reliabilities substantially: hardiness $\alpha=.82$, commitment $\alpha=.75$, control $\alpha=.70$, challenge $\alpha=.46$ ). This measure is one of the best and most widely used measures currently available for hardiness (Funk, 1992).

Mindfulness. The Five Factor Mindfulness Questionnaire (FFMQ; Baer et al., 2006) was employed to measure mindfulness. The FFMQ is comprised of 39 items that make up five factors: observing (example item: "I sense my body, whether eating, cooking, cleaning, or talking"), describing (example item: "I'm good at finding the words to describe my feelings"), acting with awareness (example item: "I break or spill things because of carelessness, not paying attention, or thinking of something else"), non-judging of inner experience (example item: "I criticize myself for having irrational or inappropriate emotions"), and non-reactivity to inner experience (example item: "I perceive my feelings and emotions without having to react to them"), and are rated on a 5-point Likert style scale, ranging from 1 (never or very rarely true) to 5 (very often or always true). All five factors have demonstrated at least adequate internal consistency in past research ( $\alpha$ ranging from .73 to .91; Bohlmeijer, ten Klooster, Fledderus, Veehof, \& Baer, 2011). In the present study, the reliability for these factors ranged from inadequate to excellent (mindfulness $\alpha=.83$, observing $\alpha=.65$, describing $\alpha=.88$, acting $\alpha=$ .83 , non-judging $\alpha=.82$, non-reactivity $\alpha=.71$; alphas would not improve substantially, or in some cases at all, if item was removed: mindfulness $\alpha=.84$, observing $\alpha=.62$, describing $\alpha=$ .89 , acting $\alpha=.83$, non-judging $\alpha=.81$, non-reactivity $\alpha=.72$ ).

Rumination. Rumination was measured using the Rumination and Reflection Questionnaire (RRQ; Trapnell \& Campbell, 1999). The RRQ comprises 24 items (12 for each 
subscale; example item: "I often find myself reevaluating something I've done") rated on a 5point Likert style scale, ranging from 1 (Strongly disagree) to 5 (Strongly agree). The rumination subscale represents ruminative brooding, while the reflection subscale represents a less negatively valenced type of self-reflection. Both subscales have demonstrated strong reliability in past research (rumination $\alpha=.90$, reflection $\alpha=.91$; Trapnell $\&$ Campbell, 1999) as well as in the present study (rumination $\alpha=.85$, reflection $\alpha=.79$; reliabilities did not improve substantially with items dropped, $\alpha=.85$ and $\alpha=.85$, respectively).

Worry. Worry was measured using the Worry Domains Questionnaire (WDQ; Tallis, Davey, \& Bond, 1994). This measure was developed to be a suitable measure of worry in nonclinical samples. The WDQ consists of 25 items rated on a 5-point Likert style scale from 0 (not at all) to 4 (extremely). The 25 items comprise five subscales (five items in each subscale) that represent different domains of worry: relationships (example item: "I worry that I am unattractive to the opposite sex"), lack of confidence (example item: "I worry that that I cannot be assertive or express my opinions"), aimless future (example item: "I worry that I'll never achieve my ambitions"), work incompetence (example item: "I worry that I will be late for an appointment"), and financial (example item: "I worry that my money will run out). The subscales are summed to produce a global worry score. The WDQ has shown high reliability in previous research $(\alpha=.91$, test retest correlations $=.85)$ is one of the most used measures of nonpathological worry (Stober, 1997). Reliability coefficients in the present study ranged from inadequate to excellent (worry $\alpha=.92$, relationships $\alpha=.70$, lack of confidence $\alpha=.78$, aimless future $\alpha=.82$, work incompetence $\alpha=.71$, financial $\alpha=.83$; reliabilities would not improve substantially, if at all, after item removal, worry $\alpha=.92$, relationships $\alpha=.69$, lack of confidence $\alpha=.77$, aimless future $\alpha=.80$, work incompetence $\alpha=.74$, financial $\alpha=.85$ ) 
Neuroticism. To measure neuroticism, participants completed items from the International Personality Item Pool for neuroticism (NEO-domain; IPIP-N; Goldberg, 1999). This scale consists of 20 items (example item: "I often feel blue"), rated on a 5-point Likert style scale from 1 (very inaccurate) to 5 (very accurate). This scale has shown strong internal consistency in previous research $(\alpha=.91$; Goldberg, 1999) as well as in the present study ( $\alpha=$ .90; alpha would not improve substantially with item removal, $\alpha=.90$ ).

Anxiety. The State-Trait Inventory for Cognitive and Somatic Anxiety (STICSA; Ree, French, MacLeod, \& Locke, 2008) was used to assess cognitive and somatic anxiety. The STICSA is comprised of 21 items (example items: cognitive: "I keep busy to avoid uncomfortable thoughts"; somatic: "My heart beats fast"), ranging from 1 (not at all) to 4 (very much so). This scale has been shown to have high Cronbach's alphas of over .80 across ethnic groups (Lancaster, Melka, Klein, \& Rodriguez, 2015). In the present study, reliabilities ranged from adequate to excellent (trait anxiety $\alpha=.85$, trait cognitive $\alpha=.79$, trait somatic $\alpha=.81$ ) and would not improve substantially, if at all, with item removal (trait anxiety $\alpha=.85$, trait cognitive $\alpha=.78$, trait somatic $\alpha=.81$ ).

The Symptom Checklist - 90- Revised (SC90R; Derogatis, 1977) somatization scale will also be employed to assess anxiety. This subscale of the SC90R consists of 12 items (example item: "In the past week, I have been bothered by soreness of muscles") rated on a 5-point Likert style scale, ranging from 1 (not at all) to 5 (extremely). This scale is one of the most widely used measures of psychopathology symptoms and the somatology scale has an alpha of .90 according to previous research (Schwarzald, Weisenberg, \& Solomon, 1991) and .87 in the present study (.87 if item removed). 
Health. The Self-rated health scale was used to assess health (SRHS; Krause \& Hayward, 2014). This measure has three items rated on Likert style scales: (1) "How would you rate your overall health at the present time?" (ranging from 1 - poor, to 4 -excellent), (2) "In general, how satisfied are you with your health?" (ranging from 1- not very satisfied, to 5completely satisfied), and (3) "Would you say your health is better, about the same, or worse than most people of your age?" (ranging from 1 -worse, to 3 - better). The SRHS has demonstrated good reliability in previous research (estimated at .83; Krause \& Hayward, 2014). In the present study, the SRHS demonstrated adequate reliability $(\alpha=.76$; item removal would not substantially improve alpha, $\alpha=.75)$.

Coping. A single-item coping measure was developed for use in this study. The item (“How well do you feel that you can cope with the stressors in your life?") is rated on a fourpoint Likert style scale, ranging from 1 (Not very well) to 4 (very well).

\section{Procedure}

Prior to completing the questionnaires, participants were given letters of information to read, and informed consent forms to sign (see Appendix B). Once signed, participants completed paper questionnaires in a classroom-like setting. Questionnaires required approximately 25 to 50 minutes to complete. Once participants finished their questionnaires, they were debriefed (see Appendix C) and thanked for their time and contribution.

\section{Results}

\section{Descriptive Statistics}

Means, standard deviations, and Cronbach's alphas for the current study are reported in Table 1. All scales and subscales reached at least adequate levels of internal consistency ( $\alpha=$ 
$.70)$ except for the observing subscale of the FFMQ measure $(\alpha=.65)$, and the control and challenge subscales of the DRS (.67 and .38, respectively).

Table 1. Descriptive statistics and Cronbach's alphas for variables in present study.

\begin{tabular}{cccc}
\hline & Mean & Standard Deviation & Cronbach's $\alpha$ \\
\hline Rumination & 41.17 & 7.03 & .85 \\
Reflection & 38.68 & 6.49 & .79 \\
Worry (aggregate) & 43.21 & 18.28 & .92 \\
Worry (relationships) & 7.499 & 4.26 & .70 \\
Worry (lack of & 8.33 & 4.45 & .78 \\
confidence) & & & .82 \\
Worry (aimless & 9.01 & 4.91 & .71 \\
future) & & & .83 \\
Worry (work & 10.39 & 4.02 & .83 \\
incompetence) & & & .82 \\
Worry (financial) & 8.13 & 4.85 & \\
Mindfulness & 119.91 & 5.62 & \\
(aggregate) & & & \\
Mindfulness & 24.88 & 5.13 & \\
(judging) & & & \\
Mindfulness & 26.91 & & \\
(describing) & & & \\
Mindfulness (acting) & & & \\
\hline
\end{tabular}




\begin{tabular}{|c|c|c|c|}
\hline $\begin{array}{l}\text { Mindfulness } \\
\text { (observing) }\end{array}$ & 21.76 & 4.24 & .65 \\
\hline $\begin{array}{l}\text { Mindfulness } \\
\text { (nonreactivity) }\end{array}$ & 21.72 & 3.69 & .71 \\
\hline $\begin{array}{l}\text { Hardiness } \\
\text { (aggregate) }\end{array}$ & 86.08 & 11.92 & .81 \\
\hline Hardiness (control) & 31.08 & 4.95 & .67 \\
\hline Hardiness (challenge) & 25.08 & 4.00 & .38 \\
\hline $\begin{array}{c}\text { Hardiness } \\
\text { (commitment) }\end{array}$ & 29.91 & 5.63 & .74 \\
\hline Neuroticism & 55.35 & 12.93 & .90 \\
\hline Health & 8.33 & 1.82 & .76 \\
\hline $\begin{array}{l}\text { Trait anxiety } \\
\text { (aggregate) }\end{array}$ & 42.51 & 9.12 & .85 \\
\hline $\begin{array}{l}\text { Trait cognitive } \\
\text { anxiety }\end{array}$ & 21.47 & 5.05 & .79 \\
\hline Trait somatic anxiety & 21.09 & 6.00 & .81 \\
\hline Somatization (SC90) & 20.98 & 8.19 & .87 \\
\hline Coping & 2.76 & .77 & \\
\hline
\end{tabular}

\section{Sex differences and correlations with age}

Possible sex differences in scale scores were examined using a series of independent $t$ tests. As well, we examined the correlations between the scales and age; sex differences and 
associations with age are displayed in Table 2. To further control for Type I error, only significance for results with $p<0.01$ (two-tailed) will be reported for all statistics. Levene's Ftest for Equality of Variance was nonsignificant for all variables. Women scored significantly higher on rumination, worry and its lack of confidence and work incompetence subscales, neuroticism, trait anxiety and its somatic anxiety subscale, and somatization; men scored significantly higher in the judging subscale of mindfulness, the challenge subscale of hardiness, health, and ability to cope with stressors. In regard to correlations with age, age was significantly, but weakly negatively correlated. It must be noted, however, that there was relatively little variance in the age of the sample $(\mathrm{SD}=3.71)$ and the vast majority of the sample was fairly young $(\mathrm{M}=19.46$ years of age); thus these correlations should be interpreted with caution.

Table 2. Sex differences and correlations with age

\begin{tabular}{|c|c|c|c|c|c|}
\hline & $\begin{array}{c}\text { Men Mean } \\
\text { (SD) }\end{array}$ & $\begin{array}{c}\text { Women } \\
\text { Mean (SD) }\end{array}$ & $F$ & $t(\mathrm{df})$ & $\begin{array}{c}r \text { with } \\
\text { age }\end{array}$ \\
\hline Rumination & $39.84(7.38)$ & $42.05(6.70)$ & 4.83 & $\begin{array}{l}2.47 * \\
(251)\end{array}$ & -.01 \\
\hline Reflection & $38.33(6.16)$ & $38.97(6.71)$ & .08 & .77 (249) & $-.18 *$ \\
\hline Worry & 39.27 & 45.56 (17.69) & .27 & $2.69 *$ & -.09 \\
\hline (aggregate) & (18.65) & & & $(248)$ & \\
\hline $\begin{array}{l}\text { Worry } \\
\text { (relationships) }\end{array}$ & $6.85(4.15)$ & $7.86(4.30)$ & .02 & $1.85(253)$ & -.11 \\
\hline $\begin{array}{c}\text { Worry (lack of } \\
\text { confidence) }\end{array}$ & $7.40(4.31)$ & $8.89(4.47)$ & .40 & $\begin{array}{l}2.64 * \\
(253)\end{array}$ & -.02 \\
\hline
\end{tabular}




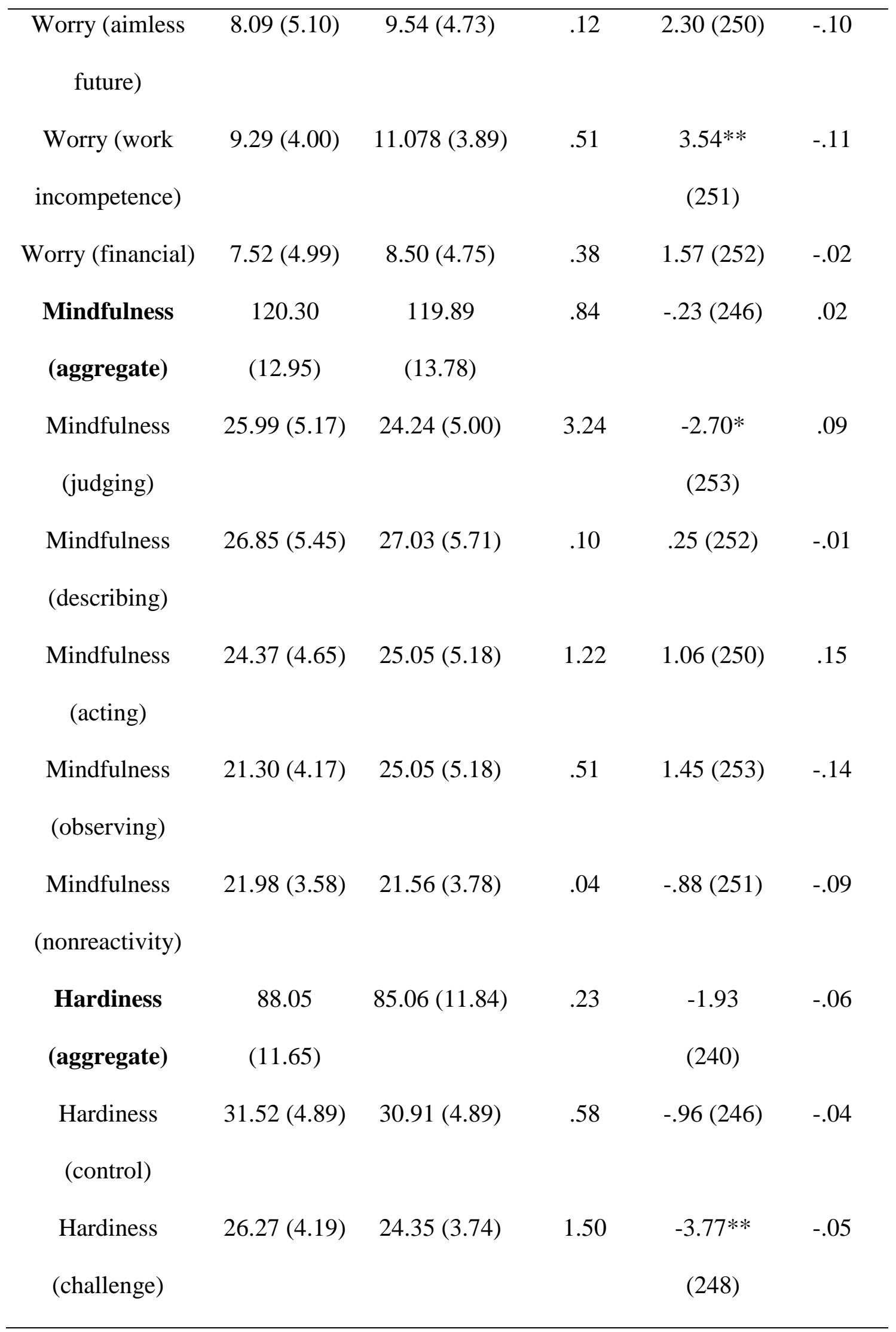




\begin{tabular}{|c|c|c|c|c|c|}
\hline $\begin{array}{c}\text { Hardiness } \\
\text { (commitment) }\end{array}$ & $30.26(5.50)$ & $29.80(5.67)$ & .06 & $-.63(245)$ & -.06 \\
\hline Neuroticism & $\begin{array}{l}50.47 \\
(13.26)\end{array}$ & 58.39 (11.80) & 2.08 & $\begin{array}{l}4.94 * * \\
(248)\end{array}$ & .04 \\
\hline Health & $9.13(1.59)$ & $7.82(1.79)$ & .75 & $\begin{array}{c}-5.93 * * \\
(252)\end{array}$ & -.07 \\
\hline $\begin{array}{c}\text { Trait anxiety } \\
\text { (aggregate) }\end{array}$ & $40.17(8.53)$ & $43.89(9.18)$ & .71 & $\begin{array}{l}3.20^{*} \\
(246)\end{array}$ & -.03 \\
\hline $\begin{array}{c}\text { Trait cognitive } \\
\text { anxiety }\end{array}$ & $20.49(5.12)$ & 22.08 (4.94) & .09 & $2.45(250)$ & -.07 \\
\hline $\begin{array}{c}\text { Trait somatic } \\
\text { anxiety }\end{array}$ & $19.73(5.19)$ & $21.80(6.23)$ & 1.76 & $\begin{array}{l}2.73 * \\
(248)\end{array}$ & .02 \\
\hline $\begin{array}{l}\text { Somatization } \\
\text { (SC90) }\end{array}$ & $18.82(7.00)$ & $22.12(8.44)$ & 2.53 & $\begin{array}{l}3.23 * \\
(250)\end{array}$ & -.02 \\
\hline Coping & $2.93(.79)$ & $2.65(.73)$ & .09 & $\begin{array}{l}-2.90 * \\
(254)\end{array}$ & -.09 \\
\hline
\end{tabular}

$* p<0.01 ; * * p<0.001$ two-tailed.

\section{Exploratory Factor Analysis}

The Kaiser-Meyer-Olkin test for sampling adequacy (KMO) indicated that the data was an excellent fit for factor analysis $(\mathrm{KMO}=.90)$. Thus, all assessed measures were submitted to Principal Axis Factoring (PAF; see Table 3) with Oblimin rotaion and Kaiser normalization. Two factors emerged based on the scree plot; the first factor comprised rumination, the nonreacting, acting, describing, and judging facets of mindfulness, trait somatic anxiety, trait 
cognitive anxiety, all three hardiness components, and all five domains of worry and accounted for $39.24 \%$ of the variance. The second factor was ill-defined, as it only comprised reflection and the observing facet of mindfulness and accounted for $6.89 \%$ of the variance. The factors were fairly independent of each other $(r=.06)$.

Table 3. Factor analysis pattern matrix

\begin{tabular}{ccc}
\hline & Factor 1 & Factor 2 \\
\hline Rumination (RRQ) & $\mathbf{. 5 6}$ & .34 \\
Reflection (RRQ) & -.06 & .72 \\
Non-reacting (FFMQ) & $\mathbf{- . 3 7}$ & .09 \\
Observing (FFMQ) & .16 &. $\mathbf{5 0}$ \\
Acting (FFMQ) & $\mathbf{- . 5 6}$ & -.11 \\
Describing (FFMQ) & $\mathbf{- . 4 0}$ & .31 \\
Judging (FFMQ) & $\mathbf{- . 6 5}$ & -.27 \\
Somatic Anxiety (STICSA) & $\mathbf{. 5 9}$ & .04 \\
Cognitive Anxiety (STICSA) & $\mathbf{. 7 7}$ & .29 \\
Commitment (DRS) & $\mathbf{- . 7 6}$ & .19 \\
Control (DRS) & $\mathbf{- . 7 0}$ & .22 \\
Challenge (DRS) & $\mathbf{. . 4 4}$ & .14 \\
Neuroticism (IPIP) & $\mathbf{. 8 1}$ & .08 \\
Relationships (WDQ) & $\mathbf{. 7 3}$ & .05 \\
Lack of Confidence (WDQ) & $\mathbf{. 8 2}$ & .05 \\
Aimless Future (WDQ) & $\mathbf{. 8 0}$ & .05 \\
Work (WDQ) & $\mathbf{. 3}$ & .05 \\
\hline
\end{tabular}


Financial (WDQ)

.61

$-.02$

Note. Loadings are bolded to indicate more dominant factor on which variable loads

\section{Correlations}

Bivariate correlations between all measures and their subscales are presented in table 4. The predictions that hardiness will be negatively correlated with rumination (hypothesis 1a) and worry (hypothesis 1b) was confirmed as hardiness and hardiness facets were modestly, but significantly negatively correlated with rumination (ranging from $r=-.18$ to $r=-.29$ ), and weakly to strongly negatively correlated with worry and all domains of worry (ranging from $r=$ .24 to $r=-.67$ ). In contrast to hypotheses (1c), hardiness was positively correlated with mindfulness and facets of mindfulness (ranging from $r=.23$ to $r=.51$ ), except for observing which was not significantly correlated with hardiness. Similarly, the control subscale of hardiness was positively correlated with mindfulness and all mindfulness facets (ranging from $r$ $=.18$ to $r=.44$ ), except for the uncorrelated observing facet, and the commitment subscale of hardiness was positively correlated with mindfulness and all mindfulness facets (ranging from $r$ $=.34$ to $r=.47$ ), except for observing and nonreacting which were not significantly correlated with commitment. The challenge subscale was positively correlated with mindfulness $(r=.27)$, judging $(r=.29)$, acting $(r=.17)$, and nonreactivity $(r=.23)$, but was unrelated to observing and describing.

The prediction (hypothesis 2a) that worry and rumination will be significantly positively correlated was supported as worry and all domains of worry were significantly positively correlated with rumination with correlation coefficients ranging from $r=.30$ to $r=.52$. The predictions that mindfulness will be negatively correlated with rumination (hypothesis $3 a$ ) and worry (hypothesis 3b) was also supported as they were both moderately negatively correlated ( $r$ 
$=-.43$ and $r=-.53$, respectively). Moreover, all domains of worry were similarly negatively correlated with trait mindfulness. Interestingly, not all facets of mindfulness were negatively correlated with rumination and worry as the observing facet was weakly positively correlated with rumination and worry $(r=.26$ and $r=.20$, respectively; not significantly correlated with the relationships, lack of confidence, and financial subscales of worry), and the describing facet was not significantly correlated with rumination, but was significantly correlated with worry $(r=-$ $.27)$.

The predictions that hardiness and mindfulness will be positively correlated with health outcomes (hypotheses $4 \mathrm{a}$ and $4 \mathrm{~b}$, respectively) and negatively correlated with anxiety and neuroticism (hypotheses $4 \mathrm{c}$ and $4 \mathrm{~d}$, respectively) were also supported. Hardiness and the control and commitment hardiness subscales were significantly positively correlated with health (ranging from $r=.24$ to $r=.31$ ) and coping (ranging from $r=.38$ to $r=.42$ ). Furthermore, hardiness and all hardiness subscales were negatively correlated with neuroticism (ranging from $r=-.36$ to $r=-.60$ ), trait anxiety (as well as both cognitive and somatic subscales; ranging from $r$ $=-.20$ to $r=-.62$ ), and somatization (SC-90r; ranging from $r=-.20$ to $r=-.51$ ). Mindfulness was significantly, albeit weakly, positively correlated with health $(r=.24)$, although the describing, acting, and observing facets were not significantly correlated with health (significant correlations ranging from $r=.20$ to $r=.23$ ); this was also the case for the relationship between mindfulness and coping, as there was a weak positive relationship between these two measures $(r=.35)$ and the mindfulness facets, except for the observing facet which showed a non-significant (but approaching significance) negative relationship (significant relationships ranged from $r=.21$ to $r$ $=.35)$. Moreover, mindfulness was negatively correlated with neuroticism $(r=-.54)$; all except for one of the mindfulness facets were also negatively correlated with neuroticism (significant 
correlations ranging from $r=-.27$ to $r=-.57$ ), while the observing facet was not significantly correlated with neuroticism. In the same vein, mindfulness, the judging, and acting subscales were negatively correlated with trait anxiety and both trait anxiety subscales (correlations ranging from $r=-14$ to $r=-.65$ ), while the observing facet was weakly positively correlated with trait anxiety and its subscales. The describing and nonreacting facets were positively correlated with trait anxiety and its cognitive anxiety subscale, but were not correlated with its somatic anxiety subscale. Similarly, mindfulness and its judging and describing facets were significantly negatively correlated with the SC-90r somatization scale (ranging from $r=-.31$ to $r$ $=-.38)$, while observing was positively correlated with somatization $(r=.21)$; acting and nonreacting were not significantly correlated with somatization. 
Table 4. Intercorrelations between all measures and facet scores

\begin{tabular}{|c|c|c|c|c|c|c|c|c|c|c|c|c|c|c|c|c|c|c|c|c|c|c|c|c|c|}
\hline & 1 & 2 & 3 & 4 & 5 & 6 & 7 & 8 & 9 & 10 & 11 & 12 & 13 & 14 & 15 & 16 & 17 & 18 & 19 & 20 & 21 & 22 & 23 & 24 & 25 \\
\hline \multicolumn{26}{|l|}{ 1. Rumination } \\
\hline 2. Reflection & $.21^{*}$ & & & & & & & & & & & & & & & & & & & & & & & & \\
\hline $\begin{array}{l}\text { 3. Worry } \\
\text { (aggregate) }\end{array}$ & $.48 * *$ & .02 & & & & & & & & & & & & & & & & & & & & & & & \\
\hline $\begin{array}{l}\text { 4. Worry } \\
\text { (relationships) }\end{array}$ & $.41^{* *}$ & .03 & .81 ** & & & & & & & & & & & & & & & & & & & & & & \\
\hline $\begin{array}{l}\text { 5. Worry (lack } \\
\text { of confidence) }\end{array}$ & $.52^{* * *}$ & .07 & $.83^{* *}$ & $.72^{* * *}$ & & & & & & & & & & & & & & & & & & & & & \\
\hline $\begin{array}{l}\text { 6. Worry } \\
\text { (aimless future) }\end{array}$ & $.42 * *$ & -.001 & $.88^{* * *}$ & $.64 * *$ & $.63^{* *}$ & & & & & & & & & & & & & & & & & & & & \\
\hline $\begin{array}{l}\text { 7. Worry (work } \\
\text { incompetence) }\end{array}$ & $.37 * *$ & .07 & $.83 * *$ & $.55 * *$ & $.65 * *$ & $.72 * *$ & & & & & & & & & & & & & & & & & & & \\
\hline $\begin{array}{l}\text { 8. Worry } \\
\text { (financial) }\end{array}$ & $.30 * *$ & -.04 & $.76 * *$ & $.49 * *$ & $.46 * *$ & $.60^{\text {** }}$ & $.56^{* *}$ & & & & & & & & & & & & & & & & & & \\
\hline $\begin{array}{l}\text { 9. Mindfulness } \\
\text { (aggregate) }\end{array}$ & $-.43^{* *}$ & $.18^{*}$ & $-.53^{* *}$ & $-.41^{* * *}$ & $-.53 * *$ & $-.46^{* *}$ & $-.43^{* * *}$ & $-.33^{* * *}$ & & & & & & & & & & & & & & & & & \\
\hline $\begin{array}{l}\text { 10. Mindfulness } \\
\text { (judging) }\end{array}$ & $-.60^{* * *}$ & -.14 & $-.56^{* * *}$ & $-.44 * *$ & $-.45 * *$ & $-.48^{* *}$ & $-.50^{* * *}$ & $-.37^{* * *}$ & $.65 * *$ & & & & & & & & & & & & & & & & \\
\hline $\begin{array}{l}\text { 11. Mindfulness } \\
\text { (describing) }\end{array}$ & -.15 & $.23^{* * *}$ & $-.27^{* *}$ & $-.21 *$ & $-.35 * *$ & $-.23 * *$ & $-.26^{* * *}$ & -.12 & $.71^{* *}$ & $.29^{* *}$ & & & & & & & & & & & & & & & \\
\hline $\begin{array}{l}\text { 12. Mindfulness } \\
\text { (acting) }\end{array}$ & $-.30^{* * *}$ & -.08 & $-.50^{* *}$ & $-.41^{* * *}$ & $-.40^{* * *}$ & $-.49 * *$ & $-.39 * *$ & $-.33^{* * *}$ & $.59 * *$ & $.40^{* *}$ & $.21 *$ & & & & & & & & & & & & & & \\
\hline $\begin{array}{l}\text { 13. Mindfulness } \\
\text { (observing) }\end{array}$ & $.26 * *$ & $.42 * *$ & $.20^{*}$ & .14 & .13 & $.20^{*}$ & $.21^{*}$ & .14 & $.30 * *$ & $-.25 * *$ & .14 & -.12 & & & & & & & & & & & & & \\
\hline $\begin{array}{l}\text { 14. Mindfulness } \\
\text { (nonreactivity) }\end{array}$ & $-.42 * *$ & $.14 *$ & $-.27^{* *}$ & $-.20^{*}$ & $-.27 * *$ & $-.21 *$ & $-.20^{*}$ & $-.25^{* * *}$ & $.55^{* *}$ & $.29^{* *}$ & $.22 * *$ & .05 & $.19 *$ & & & & & & & & & & & & \\
\hline $\begin{array}{l}\text { 15. Hardiness } \\
\text { (aggregate) }\end{array}$ & $-.29 * *$ & $.17^{*}$ & $-.67^{* * *}$ & $-.54 * *$ & $-.60^{* *}$ & $-.60^{* *}$ & $-.53 * *$ & $-.49 * *$ & $.51 * *$ & $.44 * *$ & $.36 * *$ & $.44 * *$ & -.14 & $.23^{* * *}$ & & & & & & & & & & & \\
\hline $\begin{array}{l}\text { 16. Hardiness } \\
\text { (control) }\end{array}$ & $-.18^{*}$ & .15 & $-.57^{* *}$ & $-.46^{* * *}$ & $-.53 * *$ & $-50^{* * *}$ & $-.44 * *$ & $-.38 * *$ & $.44 * *$ & $.35^{* *}$ & $.37 * *$ & $.36^{* *}$ & -.14 & $.18^{*}$ & $.87^{* *}$ & & & & & & & & & & \\
\hline $\begin{array}{l}\text { 17. Hardiness } \\
\text { (challenge) }\end{array}$ & $-20^{*}$ & .16 & $-.36^{* *}$ & $-.24 * *$ & $-.33 * *$ & $-.30^{* * *}$ & $-.30^{* * *}$ & $-.31 * *$ & $.27 * *$ & $.29 * *$ & .10 & $.17^{*}$ & -.04 & $.23^{* * *}$ & $.66 * *$ & $.37 * *$ & & & & & & & & & \\
\hline $\begin{array}{l}\text { 18. Hardiness } \\
\text { (commitment) }\end{array}$ & $-.27^{* * *}$ & .13 & $-.64 * *$ & $-.53^{* * *}$ & $-.54 * *$ & $-.58 * *$ & $-.48^{* * *}$ & $-.46^{* * *}$ & $.46^{* *}$ & $.38 * *$ & $.34 * *$ & $.47^{* * *}$ & -.15 & .15 & $.88 * *$ & $.69 * *$ & $.35 * *$ & & & & & & & & \\
\hline 19. Neuroticism & $.61 * *$ & .02 & $.69 * *$ & $.60^{* * *}$ & $.69 * *$ & $.60^{* * *}$ & $.53 * *$ & $.44 * *$ & $-.54^{* * *}$ & $-.57 * *$ & $-.27 * *$ & $-.35^{* * *}$ & .15 & $-.45 * *$ & $-.60^{* * *}$ & $-.53 * *$ & $-.36 * *$ & $-.50^{* * *}$ & & & & & & & \\
\hline 20. Health & $-.24 * *$ & .08 & $-.35 * *$ & $-.34 * *$ & $-.33^{* *}$ & $-.30^{* *}$ & $-.26^{* *}$ & $-.26^{* * *}$ & $.24 * *$ & $.20^{*}$ & .07 & .15 & .03 & $.23 * *$ & $.31^{* *}$ & $.24 * *$ & .15 & $.31 * *$ & $-.50 * *$ & & & & & & \\
\hline $\begin{array}{l}\text { 21. Trait } \\
\text { anxiety } \\
\text { (aggregate) }\end{array}$ & $.60 * *$ & .10 & $.72 * *$ & $.57 * *$ & $.65 * *$ & $.64 * *$ & $.61 * *$ & $.49^{* *}$ & $-.53 * *$ & $-.63 * *$ & $-.23 * *$ & $-.55 * *$ & $.29 * *$ & $-.24 * *$ & $-.62 * *$ & $-.54 * *$ & $-29^{* * *}$ & $-.61 * *$ & $.72^{* *}$ & $-.38^{* * *}$ & & & & & \\
\hline $\begin{array}{l}\text { 22. Trait } \\
\text { cognitive } \\
\text { anxiety }\end{array}$ & $.60^{* * *}$ & .13 & $.70^{* *}$ & $.56^{* *}$ & $.65 * *$ & $.64 * *$ & $.58 * *$ & $42^{* *}$ & $-.52 * *$ & $-.65^{* * *}$ & $-.23 * *$ & $-.48 * *$ & $.26 * *$ & $-.27^{* *}$ & $-.55 * *$ & $-.48 * *$ & $-.30^{* * *}$ & $-.50^{* *}$ & $.69 * *$ & $-.26 * *$ & $.79 * *$ & & & & \\
\hline $\begin{array}{l}\text { 23. Trait } \\
\text { somatic anxiety }\end{array}$ & $.28 * *$ & .03 & $.51 * *$ & $40^{* * *}$ & $.44 * *$ & $.43 * *$ & $.44 * *$ & $.38^{* * *}$ & $-.36^{* * *}$ & $-.40 * *$ & -.16 & $-.43 * *$ & $.20^{*}$ & -.14 & $-.49^{* * *}$ & $-.43 * *$ & $-.20^{*}$ & $-.50^{* *}$ & $.51^{* *}$ & $-.34 * *$ & $.85 * *$ & $.36 * *$ & & & \\
\hline $\begin{array}{l}\text { 24.Somatization } \\
\text { (SC90) }\end{array}$ & $.18^{*}$ & -.02 & $.46 * *$ & $.35^{* *}$ & $.41^{* * *}$ & $.38 * *$ & $.41^{* *}$ & $.34^{* *}$ & $-.31 * *$ & $-.38^{* * *}$ & -.16 & $-.33^{* *}$ & $.21^{*}$ & -.11 & $-.51^{1 * *}$ & $-.51 * *$ & $-.20^{*}$ & $-.49^{* * *}$ & $.49^{* *}$ & $-.29 * *$ & $.71 * *$ & $.38^{* * *}$ & $.76^{* *}$ & & \\
\hline 25. Coping & $-.34 * *$ & .06 & $-.41^{* * *}$ & $-.35^{* * *}$ & $-.37 * *$ & $-.38^{* * *}$ & $-.39 * *$ & $-.28^{* * *}$ & $.35^{* *}$ & $.33 * *$ & $.24 * *$ & $.21^{*}$ & -.11 & $.32^{* *}$ & $.42 * *$ & .39 ** & .15 & $.38 * *$ & $-.62^{* *}$ & $.35 * *$ & $-.44 * *$ & $-.36^{* * *}$ & $-.35 * *$ & $-.32^{* * *}$ & \\
\hline
\end{tabular}

$* p<0.01 ; * * p<0.001$ two-tailed. 
The prediction that perseverative cognitions traits will be negatively correlated with health and coping were also supported; rumination (hypothesis 5a) and worry (hypothesis 5b) were negatively correlated with health ( $r=-.24$ and $r=-.35$, respectively) and coping ( $r=-.34$ and $r=-.41$, respectively). All domains of worry were similarly negatively correlated with health (ranging from $r=-.26$ to $r=-.34$ ), as well as for coping (ranging from $r=-.28$ to $r=-.39$ ). Rumination was positively correlated with neuroticism $(r=.61)$, trait anxiety $(r=.60)$, trait cognitive anxiety $(r=.60)$, trait somatic anxiety $(r=.28)$, and SC-90r somatization $(r=.18)$, supporting the hypotheses (hypothesis $5 \mathrm{c}$ ) that rumination will be positively correlated with neuroticism and anxiety. As expected (hypothesis 5d), worry was positively correlated with neuroticism $(r=.69)$, trait anxiety $(r=.72)$, trait cognitive anxiety $(r=.70)$, trait somatic anxiety $(r=.51)$, and SC90r somatization $(r=.46)$. All domains of worry were similarly positively correlated with the neuroticism and anxiety measures (ranging from $r=.34$ to $r=.69$ ).

\section{Partial Correlations}

Table 5 presents partial correlations controlling for neuroticism. The prediction that the negative correlations between hardiness and rumination (hypothesis 1d) and worry (hypothesis 1e) will be attenuated, but still significant when neuroticism is statistically controlled, was partially supported. Regarding rumination, the strength of the relationship was reduced and became positive, although nonsignificant. Out of the three dimensions of hardiness, only the relationship between rumination and control was significant and positive $(r=.22)$, while the relationships between rumination and the challenge and commitment dimensions became positive and nonsignificant. The results pertaining to the relationship between hardiness and worry when controlling for neuroticism were more consistent with our hypothesis. Hardiness and the 
Table 5. Partial correlations, controlling for neuroticism, between all measures

\begin{tabular}{|c|c|c|c|c|c|c|c|c|c|c|c|c|c|c|c|c|c|c|c|c|c|c|c|c|}
\hline & 1 & 2 & 3 & 4 & 5 & 6 & 7 & 8 & 9 & 10 & 11 & 12 & 13 & 14 & 15 & 16 & 17 & 18 & 19 & 20 & 21 & 22 & 23 & 24 \\
\hline \multicolumn{25}{|l|}{ 1. Rumination } \\
\hline 2. Reflection & $.25^{* * *}$ & & & & & & & & & & & & & & & & & & & & & & & \\
\hline $\begin{array}{l}\text { 3. Worry } \\
\text { (aggregate) }\end{array}$ & .09 & .01 & & & & & & & & & & & & & & & & & & & & & & \\
\hline $\begin{array}{l}\text { 4. Worry } \\
\text { (relationships) }\end{array}$ & .06 & .02 & $.68 * *$ & & & & & & & & & & & & & & & & & & & & & \\
\hline $\begin{array}{l}\text { 5. Worry (lack } \\
\text { of confidence) }\end{array}$ & .16 & .08 & $.67 * *$ & $.52^{* * *}$ & & & & & & & & & & & & & & & & & & & & \\
\hline $\begin{array}{l}\text { 6. Worry } \\
\text { (aimless future) }\end{array}$ & .08 & -.02 & $.80 * *$ & $.44 * *$ & $.37 * *$ & & & & & & & & & & & & & & & & & & & \\
\hline $\begin{array}{l}\text { 7. Worry (work } \\
\text { incompetence) }\end{array}$ & .06 & .06 & $.76 * *$ & $.34 * *$ & $.46 * *$ & $.59 * *$ & & & & & & & & & & & & & & & & & & \\
\hline $\begin{array}{l}\text { 8. Worry } \\
\text { (financial) }\end{array}$ & .05 & -.06 & $.71 * *$ & $.32 * *$ & $.25 * *$ & $.47 * *$ & $.43 * *$ & & & & & & & & & & & & & & & & & \\
\hline $\begin{array}{l}\text { 9. Mindfulness } \\
\text { (aggregate) }\end{array}$ & -.15 & $.23 * *$ & $-.25 * *$ & -.13 & $-.26^{* * *}$ & $-.21 *$ & $-.20^{*}$ & -.12 & & & & & & & & & & & & & & & & \\
\hline $\begin{array}{l}\text { 10. Mindfulness } \\
\text { (judging) }\end{array}$ & $-.38 * *$ & -.16 & $-.28 * *$ & -.15 & $-.25^{* * *}$ & $-.21^{*}$ & $-.29^{* * *}$ & $-.17^{*}$ & $.50 * *$ & & & & & & & & & & & & & & & \\
\hline $\begin{array}{l}\text { 11. Mindfulness } \\
\text { (describing) }\end{array}$ & .02 & $.25^{* * *}$ & -.12 & -.05 & $-.23^{* * *}$ & -.09 & -.14 & .003 & $.69 * *$ & $.17^{*}$ & & & & & & & & & & & & & & \\
\hline $\begin{array}{l}\text { 12. Mindfulness } \\
\text { (acting) }\end{array}$ & -.11 & -.08 & $-.37^{* * *}$ & $-.26^{* * *}$ & $-.23 * *$ & $-.36^{* * *}$ & $-.26^{* *}$ & $-.20 *$ & $.50^{* * *}$ & $.26^{* * *}$ & .13 & & & & & & & & & & & & & \\
\hline $\begin{array}{l}\text { 13. Mindfulness } \\
\text { (observing) }\end{array}$ & $.21 * *$ & $.43^{* * *}$ & .14 & .06 & .04 & .14 & .15 & .08 & $.46^{* * *}$ & $.20^{*}$ & $.19 *$ & -.07 & & & & & & & & & & & & \\
\hline $\begin{array}{l}\text { 14. Mindfulness } \\
\text { (nonreactivity) }\end{array}$ & $-.21^{*}$ & $.17^{*}$ & .07 & .10 & .07 & .08 & .05 & -.06 & $.40^{* * *}$ & .04 & .11 & -.14 & $.29 * *$ & & & & & & & & & & & \\
\hline $\begin{array}{l}\text { 15. Hardiness } \\
\text { (aggregate) }\end{array}$ & .13 & $.23^{* * *}$ & $-.44 * *$ & $-.27 * *$ & $-.32 * *$ & $-.37^{* * *}$ & $-.31^{* *}$ & $-.31 * *$ & $.27 * *$ & .15 & $.25 * *$ & $.31 * *$ & -.07 & -.06 & & & & & & & & & & \\
\hline $\begin{array}{l}\text { 16. Hardiness } \\
\text { (control) }\end{array}$ & $.22^{*}$ & $.19^{*}$ & $-.34 * *$ & $-.21 *$ & $-.27 * *$ & $-.27^{* * *}$ & $-.22^{* *}$ & $-.20 *$ & $.22 *$ & .07 & $.27 * *$ & $.22 *$ & -.07 & -.08 & $.81 * *$ & & & & & & & & & \\
\hline $\begin{array}{l}\text { 17. Hardiness } \\
\text { (challenge) }\end{array}$ & .03 & $.18^{*}$ & -.16 & -.03 & -.12 & -.11 & -.13 & $-.17 *$ & .09 & .11 & .001 & .05 & .01 & .08 & $.59^{* * *}$ & $.23 * *$ & & & & & & & & \\
\hline $\begin{array}{l}\text { 18. Hardiness } \\
\text { (commitment) }\end{array}$ & .05 & $.16^{*}$ & $-.46 * *$ & $-.33 * *$ & $-.31 * *$ & $-.40 * *$ & $-.29 * *$ & $-.31 * *$ & $.26^{* *}$ & .14 & $.25 * *$ & $.36^{* *}$ & -.09 & -.10 & $.84 * *$ & $.58^{* * *}$ & $.21^{*}$ & & & & & & & \\
\hline 19. Health & .10 & .10 & -.01 & -.06 & .03 & -.001 & .004 & -.05 & -.05 & -.11 & -.08 & -.04 & .12 & .003 & .01 & -.04 & -.04 & .08 & & & & & & \\
\hline $\begin{array}{l}\text { 20. Trait } \\
\text { anxiety } \\
\text { (aggregate) }\end{array}$ & $.16^{*}$ & .12 & $.45^{* * *}$ & $.26 * *$ & $.31 * *$ & $.37 * *$ & $.39 * *$ & $.28 * *$ & $-.23 * *$ & $-.39 * *$ & -.06 & $-.46 * *$ & $.26 * *$ & .14 & $-.33^{* * *}$ & $-.27 * *$ & -.05 & $-.41 * *$ & -.03 & & & & & \\
\hline $\begin{array}{l}21 \text {. Trait } \\
\text { cognitive } \\
\text { anxiety }\end{array}$ & $.31^{* *}$ & .16 & $.43 * *$ & $.26^{* *}$ & $.33 * *$ & $.39 * *$ & $.36^{* *}$ & $.19 *$ & $-.24 * *$ & $-.43 * *$ & -.06 & $-.35 * *$ & $.22 * *$ & .06 & $-.23 * *$ & $-.19^{*}$ & -.08 & $-.25 * *$ & .13 & $.59 * *$ & & & & \\
\hline $\begin{array}{l}\text { 22. Trait } \\
\text { somatic anxiety }\end{array}$ & -.05 & .02 & $.25 * *$ & .13 & .14 & $.18^{*}$ & $.23 * *$ & $.21^{*}$ & -.12 & -.16 & -.03 & $-.31 * *$ & .15 & .12 & $-.26 * *$ & $-.22^{*}$ & -.01 & $-.33^{* *}$ & -.12 & $.81 * *$ & .004 & & & \\
\hline $\begin{array}{l}\text { 23.Somatization } \\
\text { (SC90) }\end{array}$ & $-.18^{*}$ & -.04 & $.19^{*}$ & .09 & .11 & .12 & $.21^{*}$ & .16 & -.07 & -.15 & -.03 & $-.20 *$ & .16 & .14 & $-.32^{* * *}$ & $-.35 * *$ & -.02 & $-.32 * *$ & -.06 & .59 ** & .08 & $.68 * *$ & & \\
\hline 24. Coping & .07 & .10 & .03 & .04 & .10 & -.01 & -.09 & -.01 & .03 & -.03 & .10 & -.01 & -.03 & .06 & .07 & .10 & -.10 & .11 & .06 & .01 & .11 & -.04 & -.03 & \\
\hline
\end{tabular}

\footnotetext{
$* p<0.01 ; * * p<0.001$ two-tailed.
} 
commitment and control aspects of hardiness were still weakly to moderately negatively correlated with worry and all domains of worry (ranging from $r=-.20$ to $r=-.46$ ). The challenge dimension of hardiness was nonsignificantly correlated with worry and all worry domains, except for the financial domain $(r=-.17)$.

The hypothesis that the relationship between hardiness and mindfulness will become negative when neuroticism is statistically controlled (hypothesis 1f) was not supported. Although eliminating the effect of neuroticism weakened the relationship between hardiness and mindfulness, the relationship was still positive and significant $(r=.27)$. In a similar manner, the describing and acting facets of mindfulness were also attenuated, but still significant $(r=.25$ and $r=.31$, respectively); the observing, judging, and nonreacting facets were no longer significant. The prediction that the relationship between rumination and worry will become nonsignificant when the effect of neuroticism is statistically partialled out (hypothesis $2 b$ ) was supported. The relationship between rumination and worry (including all facets of worry) became nonsignificant.

Our hypotheses regarding the relationship between hardiness and health (hypothesis $4 \mathrm{e}$ ) and anxiety outcomes (hypothesis 4f) were only partially supported. Contrary to our hypotheses, when neuroticism was statistically controlled, the relationship between hardiness and health was almost completely attenuated and became nonsignificant, as was the case for the relationships between hardiness facets and health. Moreover, with neuroticism partialled out, hardiness and hardiness subscales were no longer significantly correlated with coping ability. Interestingly, with the effect of neuroticism statistically controlled, the relationships between hardiness and anxiety and somatization scales, although somewhat attenuated, were still significant (ranging from $r=.23$ to $r=.33$ ), as was the case for the control and commitment subscales of hardiness 
(ranging from $r=-.19$ to $r=-.41$ ). The relationships between the challenge subscale and all measures of anxiety were attenuated to nonsignificance. Taken together, these results confirm Funk's (1992) concern that hardiness measures tap into neuroticism and that the relationship of hardiness and health (arguably a central feature of hardiness) is really the effect of neuroticism (or the lack of neuroticism). Still, hardiness represents something beyond neuroticism because it is still weakly to moderately related to anxious outcomes, despite neuroticism being controlled.

\section{Discussion}

The main objective of the present study was to investigate the role of personality in health and anxiety. Specifically, the present study examined the validity and possible ways that hardiness works in relation to health and anxiety-related outcomes. Moreover, with the present study, we aimed to clarify the distinction between types of perseverative cognition; that is, worry and rumination. Although most of the hypotheses were supported, some results were contrary to expectations. Specifically, the present study demonstrated that although hardiness was positively correlated with health and coping ability, when the effect of neuroticism was statistically controlled, the relationship between hardiness and coping ability dissipated to nonsignificance. This finding echoes the concerns of Funk (1992), that hardiness measures inadvertently tap into neuroticism, even despite following Funk's recommendation of using the superior DRS hardiness measure. This presents a serious threat to the validity of hardiness as a construct, as arguably one of the central features of hardiness is the pro-health outcome it is theorized to produce. Still, although hardiness was not associated with health and coping outcomes without the effect of neuroticism, it was associated with anxiety-related outcomes. For example, after controlling for the effect of neuroticism hardiness was correlated with both somatic and cognitive anxiety, mindfulness, worry, and somatization (in the expected directions). This 
suggests that hardiness is not solely neuroticism and has a substantial mental health component that approximates a lack of anxiety, beyond the effect of neuroticism. Extant research fits into this interpretation of hardiness as well; Manning et al. (1988) found that even though hardiness did not moderate the effect of stressors on health outcomes, it did have direct effects on factors related with psychological well-being such as higher job satisfaction, fewer work stressors, higher quality of life, less negativity about life, higher levels of positive affectivity, and lower levels of anxiety and depression. In other words, hardiness is not redundant with neuroticism, but neuroticism is a key feature of hardiness; this finding corroborates Maddi et al.'s (2002) conclusion that the construct of hardiness expresses vigorous mental health. One interesting observation worth noting is that hardiness was more strongly negatively correlated with worry, after partialling out the effect of neuroticism, than was mindfulness. This suggests that hardinessbased interventions may potentially be more effective at combatting worry than mindfulnessbased interventions; still, more research must be conducted to further validate this assertion.

As expected, perseverative cognition variables were significantly positively correlated, and this correlation dissipated into nonsignificance when the effect of neuroticism was removed, indicating that neuroticism is responsible for almost all the shared variance between the two traits, replicating the finding of Muris and colleagues (2005). Bivariate correlations with other traits indicated many differences in strengths of relationships with other key variables (i.e., worry was more strongly related to hardiness, somatic anxiety, and somatization) and these differences were more salient when neuroticism was partialled out. Indeed, when neuroticism was partialled out, even rumination was weakly, but significantly correlated with positive outcomes (i.e., less somatization, the nonreacting and judging facets of mindfulness, and the control dimension of hardiness) while worry was still negatively associated with these outcomes. It is also worth 
noting explicitly that when the effect of neuroticism was removed, rumination and worry were no longer significantly associated with health nor coping. The present study contributes to the growing literature that highlights key distinctions between the two traits.

In contrast to our predictions, hardiness was significantly positively correlated with mindfulness (with the exception of the observing facet which was significantly negatively correlated); this observation held even after neuroticism was accounted for (with the exception of observing and reacting facets which were no longer significantly correlated with hardiness). This may perhaps suggest one mechanism of hardiness that contributes to better mental health and psychological well-being. Furthermore, even after controlling for neuroticism, mindfulness was negatively correlated with both types of perseverative cognition, further supporting Deyo et al.'s (2009) and Querstet and Cropley's (2013) findings that mindfulness-based interventions reduce worrying and rumination.

Regarding mindfulness, one interesting finding was that the observing facet was consistently positively correlated with maladaptive outcomes (although less so when neuroticism was statistically controlled). Baer et al. (2008) found that the relationship between the observing facet and psychological adjustment is dependant on meditation experience; that is, in community samples, the observing facet is associated with maladaptive psychological outcomes, while in samples of meditators, the observing facet was positively correlated with psychological outcomes. The sample assessed in the present study is a regular student sample; hence, our results indicating a maladaptive observing facet are consistent with Baer at al.'s (2008) findings.

Although no hypotheses were made regarding sex differences, there were sex differences found in our study. We found that women scored significantly higher overall in rumination, worry, neuroticism, anxiety, and somatization and these findings were consistent with previous 
research (e.g., Johnson \& Whisman, 2013; Lilienfield \& Hess, 2001; Mccann, Stewin, \& Short, 1991; Muris et al., 2005; Nakazato \& Shimonaka, 1989; Nolen-Hoeksema \& Jackson, 2001; Robichaud, Dugas, \& Conway, 2003; Schmitt, Realo, Voracek, \& Allik, 2008; Tamres, Janicki, $\&$ Helgeson, 2002). Men tended to score higher self-report health and coping; however because these were both self-report measures, this difference may be confounded by neuroticism, as women tend to be more neurotic and neurotic individuals may be hyper-aware of health issues (Watson \& Pennebaker, 1989).

\section{Limitations and future directions}

There are some limitations to our study that must be noted. Firstly, because of the demographic of our sample (university management and organizational studies students) there was minimal variation in age and this may limit the applicability of our findings to dissimilar populations. As well, because of the low variance in age, the correlations with age of the constructs assessed in the present study should be interpreted with caution. Another limitation of our sample is the overrepresentation of women (155 women; 101 men; 2 unspecified), however this is common in self-report studies. Future research should aim to replicate this study with a more diverse sample to assess the generalizability of this study's findings.

The type of health measure that we employed also emerged as a limitation in this study. Although the psychometric properties of the measure were sound, it is impossible to tell if neurotic individuals in our sample actually were less healthy or if these individuals underreported how healthy they were and overreported their somatic symptoms; likely, this was a combination of exaggerated health issues as well as actual health deficiencies associated with neuroticism, as past research has implicated neuroticism in both of these scenarios (e.g., Costa \& McCrae, 1985; Costa \& McCrae, 1987; Grov et al., 2009). This highlights the need for future 
hardiness and neuroticism health-related research to employ both subjective and objective (e.g., Contrada, 1989; Sandvik et al., 2013; Tomfohr et al., 2015) measures of health and anxiety, as previously suggested by Watson and Pennebaker (1989). Another limitation of the present study is that the coping measure we used was perhaps too general, as it did not distinguish between coping styles, which may be more informative. Although convenient and short, it has not been validated by previous research.

Furthermore, the internal consistency of the DRS components in the present study was inadequate, specifically for the challenge component of hardiness. Although previous research has shown that the DRS components have poor internal consistency, in the present study, the challenge component's Cronbach's alpha was unacceptably low (.38). Still, extant literature suggests that the DRS is a superior measure of hardiness (e.g., Funk, 1992), despite its low internal consistency.

The main suggestion we have for further research is to 'reopen' the question of hardiness. Research on the topic of hardiness has lulled in recent years, yet the question of what it is and how it works has not been answered satisfactorily. Research should continue to investigate the mechanics of this trait as hardiness training has been suggested as an effective psychological intervention in improving retention and GPA for students (Maddi, Harvey, Khoshaba, Fazel, \& Resurreccion, 2009; Maddi et al., 2002), reducing nurse turnover rates (Judkins, Reid, \& Furlow, 2006), improving job satisfaction and social support (Maddi, Kahn, \& Maddi, 1998), reducing depression, and increasing hope in students (Green, Grant, \& Rynsaardt, 2007). Further research on this topic could improve these interventions and potentially increase their utility for practitioners in coaching, health, employment, and educational settings. 


\section{References}

American Psychiatric Association (2013). Diagnostic and statistical manual of mental disorders (5 $5^{\text {th }}$ ed.). Washington, DC: American Psychiatric Association.

Baer, R. A., Hopkins, J., Krietmeyer, J., Smith, G. T., \& Toney, L. (2006). Using self-report assessment methods to explore facets of mindfulness. Assessment, 13, 27-45.

Baer, R. A., Smith, G. T., Lykens, E., Button, D., Krietemeyer, J., Sauer, S.,...Williams, J. M. G. (2008). Construct validity of the five facet mindfulness questionnaire in meditating and nonmeditating samples. Assessment, 15, 329-342.

Bartone, P. T., Ursano, R., Wright, K., \& Ingraham, L. (1989). The impact of military air disaster on the health of assistance workers. Journal of Nervous and Mental Disease, 177, 317-328.

Bohlmeijer, E., ten Klooster, P. M., Fledderus, M., Veehof, M., \& Baer, R. (2011). Psychometric properties of the Five Facet Mindfulness Questionnaire in depressed adults and development of a short form. Assessment, 18, 308-320.

Borkovec, T. D. (1979). Pseudo(experiential)-insomnia and idiopathic(objective) insomnia: Theoretical and therapeutic issues. Advances in Behavior Research and Therapy, 2, 27-55.

Borkovec, T. D., Ray, W. J., \& Stober, J. (1998). Worry: A cognitive phenomenon intimately linked to affective, physiological, and interpersonal behavioral processes. Cognitive Therapy and Research, 22, 561-576.

Borkovec, T. D., Robinson, E., Pruzinsky, T., \& DePree, J. A. (1983). Preliminary exploration of worry: Some characteristics and processes. Behavior Research and Therapy, 21, 9-16.

Brosschot, J. F., Gerin, W., \& Thayer, J. F (2006). The perseverative cognition hypothesis: A review of worry, prolonged stress-related physiological activation, and health. Journal of Psychosomatic Research, 60, 113-124. 
Brosschot, J. F., Van Dijk, E., \& Thayer, J. F. (2007). Daily worry is related to low heart rate variability during waking and the subsequent nocturnal sleep period. International Journal of Psychophysiology. 63, 39-47.

Brown, J. D. (1991). Staying fit and staying well: Physical fitness as a moderator of life stress. Journal of Personality and Social Psychology, 60, 555-561.

Brown, K. W., Weinstein, N., \& Creswell, J. D. (2012). Trait mindfulness modulates neuroendocrine and affective responses to social evaluative threat. Psychoneuroendocrinology, 37, 2037-2041.

Carmack, C. L., de Moor, C., Boudreaux, E., Amaral-Melendez, M., \& Brantley, P. B. (1999). Aerobic fitness and leisure physical activity as moderators of the stress-illness relation. Annals of Behavioral Medicine, 21, 251-257.

Carmody, J., Reed, G., Kristeller, J., \& Merriam, P. (2008). Mindfulness, spirituality, and healthrelated symptoms. Journal of Psychosomatic Research. 64, 393-403.

Ciesla, J. A., Reilly, L. C., Dickson, K. S., Emanuel, A. S., \& Updegraff, J. A. (2012). Dispositional mindfulness moderates the effects of stress among adolescents: Rumination as a mediator. Journal of Clinical Child \& Adolescent Psychology, 41, 760-770.

Contrada, R. J. (1989). Type A behavior, personality hardiness, and cardiovascular responses to stress. Journal of Personality and Social Psychology, 57, 895-903.

Costa, P. T., Jr., \& McCrae, R. R. (1985). Hypochondriasis, neuroticism, and aging: When are somatic complaints unfounded? American Psychologist, 40, 19-28.

Costa, P. T., Jr., \& McCrae, R. R. (1987). Neuroticism, somatic complaints, and disease: Is the bark worse than the bite? Journal of Personality, 55, 299-316. 
Davey, G. C. L. (1993). A comparison of three worry questionnaires. Behavior Research and Therapy, 31, 51-56.

Derogatis, L. R. (1977). SCL-90 administration, scoring and procedures manual 1 for the R(evised) version. Baltimore: Johns Hopkins University School of Medicine.

Desrosiers, A., Vine, V., Klemanski, D. H, \& Nolen-Hoeksema, S. (2013). Mindfulness and emotion regulation in depression and anxiety: Common and distinct mechanisms of action. Depression and Anxiety, 30, 654-661.

Deyo, M., Wilson, K. A., Ong,. J., \& Koopman, C. (2009). Mindfulness and rumination: Does mindfulness training lead to reductions in the ruminative thinking associated with depression? Explore, 5, 265-271.

Eschleman, K. J., Bowling, N. A., \& Alarcon, G. M. (2010). A meta-analytic examination of hardiness. International Journal of Stress Management, 17, 277-307.

Flett, G. L., Madorsky, D., Hewitt, P. L., \& Heisel, M. J. (2002). Perfectionism cognitions, rumination, and psychological distress. Journal of Rational-Emotive and Cognitive Behavior Therapy, 20, 33-47.

Fresco, D. M., Frankel, A. N., Mennin, D. S., Turk, C. L., \& Heimberg, R. G. (2002). Distinct and overlapping features of rumination and worry: The relationship of cognitive production to negative affective states. Cognitive Therapy and Research, 26, 179-188.

Frewen, P. A., Evans, E. M., Maraj, N., Dozois, D. J. A., \& Partridge, K. (2008). Letting go: Mindfulness and negative automatic thinking. Cognitive Therapy and Research, 32, 758774.

Funk, S. C. (1992). Hardiness: A review of theory and research. Health Psychology, 11, 335-345. 
Funk, S. C., \& Houston, B. K. (1987). A critical analysis of the Hardiness Scale's validity and utility. Journal of Personality and Social Psychology, 53, 572-578.

Goldberg, L. R. (1999). A broad-bandwidth, public domain, personality inventory measuring the lower-level facets of several five-factor models. In I. Mervielde, I. Deary, F. De Fruyt, \& F. Ostendorf (Eds.), Personality Psychology in Europe, Vol. 7 (pp. 7-28). Tilburg, The Netherlands: Tilburg University Press.

Goldman S. L., Kraemer, D. T., \& Salovey, P. (1996). Beliefs about mood moderate the relationship of stress and illness and symptom reporting. Journal of Psychosomatic Research, 41, 115-128.

Gore, S. (1978). The effect of social support in moderating the health consequences of unemployment. Journal of Health and Social Behavior, 19, 157-165.

Green, S., Grant, A., \& Rynsaardt, J. (2007). Evidence-based life coaching for senior high school students: Building hardiness and hope. International Coaching Psychology Review, 2, 2432.

Grossman, P., Niemann, L., Schmidt, S., \& Walach, H. (2004) Mindfulness-based stress reduction and health benefits - A meta-analysis. Journal of Psychosomatic Research. 57, $35-43$.

Grov E. K., Fossa, S. D., Bremnes, R. M., Dahl, O., Klepp, O., Wist, E., \& Dahl, A. A. (2009). The personality trait of neuroticism is strongly associated with long-term morbidity in testicular cancer survivors. Acta Oncologica, 48, 842-849.

Hanton, S., Neill, R., \& Evans, L. (2013). Hardiness and anxiety interpretation: An investigation into coping usage and effectiveness. European Journal of Sport Science, 13, 96-104. 
Jacobs, T. L., Shaver, P. R., Epel, E. S., Zanesco, A. P., Aichele, S. R., Bridwell, D. A.,... Saron, C. D. (2013). Self-reported mindfulness and cortisol during a shamatha meditation retreat. Health Psychology, 32, 1104-1109.

Johnson, D. P., \& Whisman, M. A. (2013). Gender differences in rumination: A meta-analysis. Personality and Individual Differences, 55, 367-374.

Jordan, C. H., Wang, W., Donatoni, L., \& Meier, B. P. (2014) Mindful Eating: Trait and state mindfulness predict healthier eating behavior. Personality and Individual Differences, 68 , 107-111.

Kabat-Zinn, J. (1994). Mindfulness meditation in everyday life. London, UK: Piatkus Books.

Kadziolka, M. J., Di Pierdomenico, E., \& Miller, C. J. (2016). Trait-like mindfulness promotes healthy self-regulation of stress. Mindfulness, 7, 236-245.

Karyadi, K. A., VanderVeen, J D., \& Cyders, M. A. (2014). A meta-analysis of the relationship between trait mindfulness and substance use behaviours. Drug and Alcohol Dependence, $143,1-10$.

Klag, S., \& Bradley, G. (2004). The role of hardiness in stress and illness: An exploration of the effect of negative affectivity and gender. British Journal of Health Psychology, 9, 137-161.

Kobasa, S. C. (1979a). Stressful life events, personality, and health: An inquiry into hardiness. Journal of Personality and Social Psychology, 37, 1-11.

Kobasa, S. C. (1979b). Personality and resistance to illness. American Journal of Community Psychology, 7, 413-423.

Kobasa, S. C., Maddi, S. R., \& Courington, S. (1981). Personality and constitution as mediators in the stress-illness relationship. Journal of Health and Social Behavior, 22, 368-378. 
Kobasa, S. C., Maddi, S. R., \& Kahn, S. (1982). Hardiness and health: A prospective study. Journal of Personality and Social Psychology. 42, 168-177.

Kobasa, S. C., Maddi, S. R., Puccetti, M. C., \& Zola, M. A. (1985). Effectiveness of hardiness, exercise and social support as resources against illness. Journal of Psychometric Research, 29, 525-533.

Kocovski, N. L., Endler, N. S., Rector, N. A., \& Flett, G. L. (2005). Ruminative coping and postevent processing in social anxiety. Behavior Research and Therapy, 43, 971-984.

Krause, N., \& Hayward, R. D. (2014) Hostility, religious involvement, gratitude, and self-rated health in late life. Research on Aging, 36, 731-752.

Kubzansky, L. D., Kawachi, I., Spiro, A., Weiss, S. T., Vokonas, P. S., \& Sparrow, D. (1997). Is worrying bad for your heart? A prospective study of worry and coronary heart disease in the normative aging study. Circulation, 95, 818-824.

Lancaster, S. L., Melka, S. E., Klein, K. P., \& Rodriquez, B. F. (2015). Ethnicity and anxiety: A psychometric evaluation of the STICSA. Measurement and Evaluation in Counseling and Development, 48, 1-14.

Lilienfield, S. O., \& Hess, T. H. (2001). Psychopathic personality traits and somatization: Sex differences and the mediating role of negative emotionality. Journal of Psychopathology and Behavioral Assessment, 23, 11-24.

Lyubomirsky, S., \& Nolen-Hoeksema, S. (1993). Self-perpetuating properties of dysphoric rumination. Journal of Personality and Social Psychology, 65, 339-345.

Lyubomirsky, S., \& Nolen-Hoeksema, S. (1995). Effects of self-focused rumination on negative thinking and interpersonal problem solving. Journal of Personality and Social Psychology, 69, 176-190. 
Lyubomirsky, S., Tucker, K. L., Caldwell, N. D., \& Berg, K. (1999). Why ruminators are poor problem solvers: Clues from the phenomenology of dysphoric rumination. Journal of Personality and Social Psychology, 77, 1041-1060.

Linville, P. W. (1987). Self-complexity as a cognitive buffer against stress-related illness and depression. Journal of Personality and Social Psychology, 54, 663-676.

Maddi S. R., Harvey, R. H., Khoshaba, D. M., Fazel, M., \& Resurreccion, N. (2009). Hardiness training facilitates performance in college. The Journal of Positive Psychology, 4, 566577.

Maddi, S. R., Kahn, S., \& Maddi, K. L. (1998). The effectiveness of hardiness training. Consulting Psychology Journal: Practice and Research, 50, 78-86.

Maddi, S. R., Khoshaba, D. M., Jensen, K., Carter, E., Lu, J. L., \& Harvey, R. H. (2002). Hardiness training for high-risk undergraduates. NACADA Journal, 22, 45-55.

Maddi, S. R., Khoshaba, D. M., Persico, M., Lu, J., Harvey, R., \& Bleecker, F. (2002). The personality construct of hardiness II. Relationships with comprehensive tests of personality and psychopathology. Journal of Research in Personality, 36, 72-85.

Manning, M. R., Williams, R. F., \& Wolfe, D. M. (1988). Hardiness and the relationship between stressors and outcomes. Work and Stress, 2, 205-216.

Mathews, A. (1990). Why worry? The cognitive function of anxiety. Behavior Research and Therapy, 6, 455-468.

Mccann, S. J. H., Stewin, L. L., \& Short, R. H. (1991). Sex differences, social desirability, masculinity, and the tendency to worry. The Journal of Genetic Psychology, 152, 295301. 
Meyer, T. J., Miller, M. L., Metzger, R. L., \& Borkovec, T. L. (1990). Development and validation of the Penn State Worry Questionnaire. Behavior Research and Therapy, 28, 487-495.

Muris, P., Roelofs, J., Rassin, E., Franken, I., \& Mayer, B. (2005). Mediating effects of rumination and worry on the links between neuroticism, anxiety and depression. Personality and Individual Differences, 39, 1105-1111.

Nakazato, K., \& Shimonaka, Y. (1989). The Japanese State-Trait Anxiety Inventory: Age and sex differences. Perceptual and Motor Skills, 69, 611-617.

Neria, Y., Guttmann-Steinmetz, S., Koenen, K., Levinovsky, L., Zakin, G., \& Dekel, R. (2001). Do attachment and hardiness relate to each other and to mental health in real-life stress? Journal of Social and Personal Relationships, 18, 844-858.

Nolan, S. A., Roberts, J. E., \& Gotlib, I. H. (1998). Neuroticism and ruminative response style as predictors of change in depressive symptomatology. Cognitive Therapy and Research, $22,445-455$.

Nolen-Hoeksema, S. (1991). Reponses to depression and their effects on the duration of depressive episodes. Journal of Abnormal Psychology, 100, 569-582.

Nolen-Hoeksema, S., \& Davis, C. G. (1999). "Thanks for sharing that": Ruminators and their social support networks. Journal of Personality and Social Psychology, 77, 801-814.

Nolen-Hoeksema, S., \& Harrel, Z. A. (2002). Rumination, depression, and alcohol use: Tests of gender differences. Journal of Cognitive Psychotherapy, 16, 391-403.

Nolen-Hoeksema, S., \& Jackson, B. (2001). Mediators of the gender difference in rumination. Psychology of Women Quarterly, 25, 37-47. 
Nolen-Hoeksema, S., \& Morrow, J. (1991). A prospective study of depression and posttraumatic stress symptoms after a natural disaster: The 1989 Loma Prieta earthquake. Journal o Personality and Social Psychology, 61, 115-121.

Nolen-Hoeksema, S., Stice, E., Wade, E., \& Bohon, C. (2007). Reciprocal relations between rumination and bulimic, substance abuse and depressive symptoms in female adolescents. Journal of Abnormal Psychology, 116, 198-207.

Nolen-Hoeksema, S., Wisco, B. E., Lyubomirsky, S. (2008). Rethinking rumination. Perspectives on Psychological Science, 3, 400-424.

Nowack, K. M. (1986). Type A, hardiness, and psychological distress. Journal of Behavioral Medicine, 9, 537-548.

Parkes, K. R., \& Rendall, D. (1988). The hardy personality and its relationship to extraversion and neuroticism. Personality and Individual Differences, 9, 785-790.

Querstret, D., \& Cropley, M. (2013). Assessing treatments used to reduce rumination and/or worry: A systematic review. Clinical Psychology Review, 33, 996-1009.

Rabkin, J. G., \& Struening, E. L. (1976). Life events, stress and illness. Science, 194, 1013-1020.

Ree, M. J., French, D., Macleod, C., \& Locke, V. (2008). Distinguishing cognitive and somatic dimensions of state and trait anxiety: development and validation of the state-trait inventory for cognitive and somatic anxiety (STICSA). Behavioural and cognitive psychotherapy, 36, 313-332.

Robichaud, M., Dugas M. J., \& Conway, M. (2003). Gender differences in worry and associated cognitive variables. Journal of Anxiety Disorders, 17, 501-516. 
Rodenberry, A., \& Renk, K. (2010). Locus of control and self-efficacy: Potential mediators of stress, illness, and utilization of health services in college students. Child Psychiatry and Human Development, 41, 353-370.

Sandvik, A. M., Bartone, P. T., Hystad, S. W., Phillips, T. M., Thayer, J. F., \& Johnsen, B. H. (2013). Psychological hardiness predicts neuroimmunological responses to stress. Psychology, Health \& Medicine, 18, 705-713.

Schmitt, D. P, Realo, A., Voracek, M., \& Allik, J. (2008). Why can’t a man be more like a woman? Sex differences in big five personality traits across 55 countries, Journal of Personality and Social Psychology, 94, 168-182.

Schwarzald, J., Weisenberg, M., \& Solomon, Z. (1991). Factor invariance of SCL-90-R: The case of combats stress reaction. Psychological Assessment, 3, 385-390.

Segerstrom, S. C., Tsao, J. C. I., Alden, L. E., \& Craske, M. G. (2000). Worry and rumination: Repetitive thought as a concomitant and predictor of negative mood. Cognitive Therapy and Research, 24, 671-688.

Sinclair, R. R., \& Tetrick, L. E. (2000). Implications of item wording for hardiness structure, relation with neuroticism, and stress buffering. Journal of Research in Personality, 34, 125.

Smith, J. M., \& Alloy, L. B. (2009). A roadmap to rumination: A review of the definition, assessment, and conceptualization of this multifaceted construct. Clinical Psychology Review, 29, 116-128.

Stober, J. (1997). Reliability and validity of two widely- used worry questionnaires: self-report and self-peer convergence. Personality and Individual Differences, 24, 887-890. 
Stober, J., \& Borkovec, T. D. (2002). Reduced concreteness of worry in generalized anxiety disorder: Findings from a therapy study. Cognitive Therapy and Research, 26, 89-96.

Stober, J., Tepperwien, S., \& Staak, M. (2000). Worrying leads to reduced concreteness of problem elaborations: Evidence for the Avoidance theory of worry. Anxiety, Stress, and Coping, 13, 217-227.

Tallis, F., Davey, G. C. L., \& Bond, A. (1994). The Worry Domains Questionnaire. In G. C. L. Davey \& F. Tallis (Eds.), Worrying. Perspectives on theory, assessment, and treatment (pp.285-297). New York: Wiley.

Tamres, L. K., Janicki, D., \& Helgeson, V. S. (2002). Sex differences in coping behavior: A meta-analytic review and an examination of relative coping. Personality and Social Psychology Review, 6, 2-30.

Taylor, M. K., Pietrobon, R., Taverniers, J., Leon, M. R., \& Fern, B. J. (2013). Relationships of hardiness to physical and mental health status in military men: A test of mediated effects. Journal of Behavioural Medicine, 36, 1-9.

Thomsen, D. K., Mehlsen, M. Y., Hokland, M., Vidik, A., Olesen, F., Avlund, K.,... Zachariae, R. (2004). Negative thoughts and health: Associations among rumination, immunity, and health care utilization in a young and elderly sample. Psychosomatic Medicine, 66, 363371.

Tomfohr, L. M., Pung, M. A., Mills, P. J., \& Edwards, K. (2015). Trait mindfulness is associated with blood pressure and interleukin-6: exploring interactions among subscales of the Five Facet Mindfulness Questionnaire to better understand relationship between mindfulness and health. Journal of Behavioral Medicine, 38, 28-38. 
Trapnell, P. D., \& Campbell, J. D. (1999). Private self-consciousness and the five-factor model of personality: Distinguishing rumination from reflection. Journal of Personality and Social Psychology, 76, 284-304.

Tucker, D. M., \& Newman, J. P. (1981). Verbal versus imaginal cognitive strategies in the inhibition of emotional arousal. Cognitive Therapy and Research, 5, 197-202.

Vrana, S. R., Cutbert, B. N., \& Lang, P. J. (1986). Fear imagery and text processing. Psychophysiology, 23, 247-253.

Watkins, E., Moulds, M., \& Mackintosh, B. (2005). Comparisons between rumination and worry in a non-clinical population. Behavior Research and Therapy, 43, 1577-1585.

Watson, D., \& Pennebaker, J. W. (1989). Health complaints, stress, and distress: Exploring the central role of negative affectivity. Psychological Review, 96, 234-254.

Weinstein, N., Brown, K. W., \& Ryan, R. M. (2009). A multi-method examination of the effects of mindfulness on stress attribution, coping, and emotional well-being. Journal of Research in Personality, 43, 374-385.

Wenzel, M., von Verson, C., Hirschmuller, S., \& Kubiak, T. (2015). Curb your neuroticism Mindfulness mediates the link between neuroticism and subjective well-being. Personality and Individual Differences, 80, 68-75.

Williams, P. G., Wiebe, D. J., \& Smith, T. W. (1992). Coping processes as mediators of the relationship between hardiness and health. Journal of Behavioral Medicine, 15, 237-255. 
Appendix A

Participant Pool Description 
In this study you will be asked to complete a number of personality and stress questionnaires. It is expected that it will take you approx. 45- 60 minutes to complete these questionnaires and will take place at the indicated location. A research assistant will meet you at this location at your chosen time slot. If you are a MOS 1021A/B student, you will receive 1 bonus percentage point toward your final course grade. To participate in this study, you must be 18 years of age or older. If you have any questions about the study, please contact Christopher Marcin Kowalski. Note: your participation is voluntary and all information will be kept confidential. 
Appendix B

Letter of Information 
Project Title: The relationship between stress and personality traits

Principal Investigators: $\underline{\text { Julie Aitken Schermer, PhD, DAN Management and Organizational }}$ Studies, Western University

Christopher Marcin Kowalski, MSc candidate, Health and Rehabilitation Sciences, Western University

\section{Letter of Information}

\section{Invitation to Participate}

You are invited to participate in a study entitled "The relationship of stress and personality traits", conducted by Christopher Marcin Kowalski, MSc candidate from the University of Western Ontario, under the supervision of Prof. Julie Aitken Schermer.

\section{Purpose of the Letter}

The purpose of this letter is to provide you with information required for you to make an informed decision regarding participation in this research.

\section{Purpose of this Study}

The purpose of this study is to examine the relationship of stress, health, and personality traits that are characterized by various responses to stress.

\section{Inclusion Criteria}

Individuals who are 18 years of age or older are eligible to participate in this study.

\section{Exclusion Criteria}

None.

\section{Study Procedures}

If you agree to participate, you will be asked to complete a series of questionnaires regarding stress, health, and personality. It is anticipated that the entire task will take approximately 45 minutes. The task will be conducted on the University of Western Ontario campus.

\section{Possible Risks and Harms}

Some of the questionnaires employed in this study contain general questions relating to negative thoughts and feelings that may cause discomfort. If you feel uncomfortable answering these types of questions, we advise that you do not participate in this study. If you feel uncomfortable answering a question, you are not obligated to answer it and can withdraw from the study at any time. Below is a list of mental health resources on campus that are available to students

Student Development Centre

Student Health Services

Peer Support Centre

8. Possible Benefits
519-661-3031

519-661-3030

http://westernusc.ca/peersupport/ 
The possible benefits to participants may be learning something about themselves and the information gathered in this study will contribute to the health and personality psychology literature.

\section{Compensation}

For your participation in this study, you will receive a bonus percentage point in your MOS $1021 \mathrm{~A} / \mathrm{B}$ course.

\section{Voluntary Participation}

Participation in this study is voluntary. You may refuse to participate, refuse to answer any questions, or withdraw from the study at any time with no effect on your future academic status. You do not waive any legal rights by participating in this research.

\section{Confidentiality}

All data collected will remain confidential and accessible only to the investigators of this study. If the results are published, your name will not be used. Once you submit your responses you cannot withdraw them because no personal identifiers are linked to your survey responses that would allow the researchers to identify them and delete them. While we will do our best to protect your information there is no guarantee that we will be able to do so. The inclusion of your age may allow someone to link the data and identify you. Representatives of The University of Western Ontario Non-Medical Research Ethics Board may contact you or require access to your study-related records to monitor the conduct of the research.

\section{Contacts for Further Information}

If you require any further information regarding this research project or your participation in the study you may contact Christopher Marcin Kowalski or Dr. Julie Aitken Schermer.
Christopher Marcin Kowalski
Julie Aitken Schermer
MSc Candidate
Professor
Health and Rehab Sciences
DAN Management

If you have any questions about your rights as a research participant or the conduct of this study, you may contact The Office of Research Ethics (519) 661-3036, email: ethics@uwo.ca.

\section{Publication}

If the results of the study are published, your name will not be used. If you would like to receive a copy of any potential study results, please contact Christopher Marcin Kowalski. 


\section{Consent Form}

Project Title: The relationship between stress and personality traits Study Investigator's Name: Julie Aitken Schermer

I have read the Letter of Information, have had the nature of the study explained to me and I agree to participate. All questions have been answered to my satisfaction.

Participant's Name (please print):

Participant's Signature:

Date:

Person Obtaining Informed Consent (please print):

Signature:

Date: 
Appendix C

Debriefing form 


\section{Debriefing}

The purpose of this study is to further investigate the personality profile of the hardy individual and to better understand the mechanisms by which hardiness relates to health. Hardiness is characterized by three personality characteristics: a sense of commitment to one's activities and surroundings, the perception that one can control or influence events and situations in one's life, and the tendency to perceive changes in life as challenges rather than stressors. By definition, hardy individuals are less likely to become ill in times of stress. The present study is looking at the relationship between hardiness, health, and stress related behaviours. More specifically, the present study will examine the relationship between hardiness and health, mindfulness, worry, neuroticism, anxiety, and rumination. The current study will help clarify how hardiness is related to different types and responses to distress. Furthermore, this study will help distinguish the difference between rumination, worry (both are similar, but distinct and the current literature is lacking on this distinction), and mindfulness. We predict that hardiness will be positively correlated with mindfulness and health, and negatively correlated with rumination, worry, anxiety, and neuroticism. Anxiety, neuroticism, worry, and rumination will all be positively inter-correlated.

Thank you very much for your participation. If you have any questions regarding this study or desire additional information, please email Christopher Marcin Kowalski, MSc candidate

Below are some of the on-campus mental health resources that are available to students.

Student Development Centre Student Health Services

Peer Support Centre
519-661-3031

519-661-3030

http://westernusc.ca/peersupport/ 
Appendix D

Ethics Approval Notice 


\section{Western University Non-Medical Research Ethics Board NMREB Delegated Initial Approval Notice}

Principal Investigator: Dr. Julie Schermer

Department \& Institution: Social SciencelManagement \& Organizational Studies, Western University

NMREB File Number: 108187

Study Title: The relationships between psychological hardiness, mindfulness, neuroticism, worry, rumination, and stress

NMREB Initial Approval Date: September 21, 2016

NMREB Expiry Date: September 21, 2017

Documents Approved and/or Received for Information:

\begin{tabular}{|l|l|l|}
\hline Document Name & Comments & Version Date \\
\hline Western University Protocol & Received September 7, 2016 & \\
\hline Letter of Information \& Consent & & $2016 / 08 / 30$ \\
\hline Instruments & Questionnaires - Received September 7, 2016 & \\
\hline Other & Debriefing - Received September 7, 2016 & \\
\hline
\end{tabular}

The Western University Non-Medical Research Ethics Board (NMREB) has reviewed and approved the above named study, as of the NMREB Initial Approval Date noted above.

NMREB approval for this study remains valid until the NMREB Expiry Date noted above, conditional to timely submission and acceptance of NMREB Continuing Ethics Review.

The Western University NMREB operates in compliance with the Tri-Council Policy Statement Ethical Conduct for Research Involving Humans (TCPS2), the Ontario Personal Health Information Protection Act (PHIPA, 2004), and the applicable laws and regulations of Ontario.

Members of the NMREB who are named as Investigators in research studies do not participate in discussions related to, nor vote on such studies when they are presented to the REB.

The NMREB is registered with the U.S. Department of Health \& Human Services under the IRB

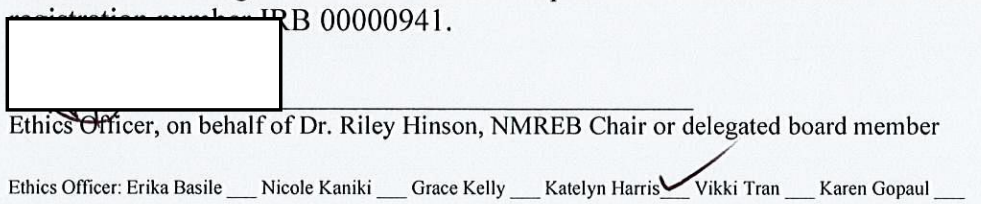




\section{Curriculum Vitae}

(March 2017)

Christopher Kowalski, B.A., M.Sc. Student

The University of Western Ontario

\section{Education}

2015

2016-2018

2018-2022

\section{BA (Honours) Psychology, University of Western Ontario}

MSc Health and Rehabilitation Sciences, University of Western Ontario

$\mathrm{PhD}$ Psychology, University of Western Ontario

\section{Employment History}

September 2017-Present

April 2017-Present

September 2011-Present

April 2016-September 2016

November 2016-April 2017
Teacher's Assistant, (Faculty of Health Sciences), University of Western Ontario

Project Manager (Love Lab;Department of Psychology), The University of Western Ontario IT Help Desk Consultant (Information Technology Services), The University of Western Ontario Research Assistant/Co-investigator (for Dr. June Cotte; marketing), Richard Ivey School of Business, The University of Western Ontario

Marketing Research Assistant (Faculty of Health Sciences), University of Western Ontario

\section{Academic Honours}

(6)Faculty of Health Sciences Graduate Conference Travel Award (2017)

(5) Western Graduate Research Scholarship (2016-2018)

(4) Dean's Honour List (2015)

(3) Dr. Jerzy Jarmasz Scholarship (2015)

(2) University of Western Ontario Staff Association Dependents' Scholarship (2011-2014)

(1) King's University Entrance Scholarship (2011)

\section{Publications}


(4) Rogoza, R., Kwiatkowska, M. M., Kowalski, C. M., \& Slaski, S. (2018). A brief tale of the two faces of narcissism and the two facets of pride. Personality and Individual Differences, 120, 43-47.

(3) Kowalski, C. M., Rogoza, R., Vernon, P. A., \& Schermer, J. A. (2018). The Dark Triad and the self-presentation variables of socially desirable responding and self-monitoring. Personality and Individual Differences, 120, 234-237.

(2) Kowalski, C. M., Vernon, P. A., \& Schermer, J. A. (2017). Vocational interests and dark personality: Are there dark career choices? Personality and Individual Differences, 104, 43-47.

(1) Kowalski, C. M., Vernon, P. A., \& Schermer, J. A. (2016). The General Factor of Personality: The relationship between the Big One and the Dark Triad. Personality and Individual Differences, 88, 256-260.

Published Abstracts

Kowalski, C. M., Vernon, P. A., \& Schermer, J. A. (2016). The general factor of personality (GFP) and the dark triad. Personality and Individual Differences, 101, 492.

Presentations at Conferences

(2) Rogoza, R., Kowalski, C. M., \& Schermer, J. A. (2017). Comparison of the Dark Triad and Narcissistic Admiration and Rivalry within the framework of the Circumplex Model of Personality Metatraits. Poster presented at the International Society for the Study of Individual Differences Conference, Warsaw, Poland.

(1) Kowalski, C. M., Vernon, P. A., \& Schermer, J. A. (2015). The General Factor of Personality: The Relationship between the Big One and the Dark Triad. Poster presented at the International Society for the Study of Individual Differences Conference, London, Canada.

\section{$\underline{\text { Other Publications }}$}

Kowalski, C. M. \& Schermer, J. A. (2017). Investigative occupational types. In Zeigler-Hill, V. \& Shackelford, T. (eds.), Encyclopedia of Personality and Individual Differences. Springer.

Kowalski, C. M. \& Schermer, J. A. (in press). Social occupational types. In Zeigler-Hill, V. \& Shackelford, T. (eds.), Encyclopedia of Personality and Individual Differences. Springer.

Kowalski, C. M., \& Czajka, J. (2015). Preventing relationship abuse with the Health Belief Model. Western Undergraduate Psychology Journal, 3, 104-113. 


\section{Editorial Service}

October 2015-present: Reviewer, Personality and Individual Differences

September 2015- April 2016: Editor, Western Undergraduate Psychology Journal

\section{Administrative Experience}

Student Clubs, University Students' Council, University of Western Ontario

2015 - 2016: Polish Students' Union- Vice President of Finance

2013 - 2014: Polish Students' Union- President

\section{Volunteer Research Experience}

2014 -April 2016: Research Assistant, Dr. Victoria Esses's lab, Department of Psychology Duties

- Thin slice video coding of participant interactions

- Entry of behavioural measure scores into SPSS

- Leading participants through experimental trials

2013 - 2014: Research Assistant, Dr. Lorne Campbell's lab, Department of Psychology Duties

- Confederate in economic game study

\section{Current Projects}

Large cross-cultural investigation of narcissism, envy, humour styles, self-esteem, shyness, loneliness, and individualism/collectivism.

International collaboration investigating the Dark Triad in relation to the Circumplex of Personality Metatraits.

An Investigation of the Dark Triad and fluid intelligence 


\section{Community Service}

- Organized "Balkan Flood Relief Euro Party" to raise money for Balkan Flood Relief (raising \$700) - June, 2014

- Co-organized "Balkan Flood Relief Soccer Tournament" to raise money for Balkan Flood Relief (raising \$300) - June, 2014

- Volunteered at London Food Bank - October, 2013 - March, 2014

- Volunteered at Sisters of St. Joseph Soup Kitchen - December, 2013, 2016

- $\quad$ Started and managed Gofundme campaign to raise money for child's Leukemia treatment (raising $\$ 6,118$ )

- Organized "Team Kubus Euro Party" to raise money for child's Leukemia treatment (raising approx. \$800)- February, 2017 